NBER WORKING PAPER SERIES

\title{
IS PUBLIC EQUITY DEADLY? EVIDENCE FROM WORKPLACE SAFETY AND PRODUCTIVITY TRADEOFFS IN THE COAL INDUSTRY
}

\author{
Erik P. Gilje \\ Michael D. Wittry \\ Working Paper 28798 \\ http://www.nber.org/papers/w28798 \\ NATIONAL BUREAU OF ECONOMIC RESEARCH \\ 1050 Massachusetts Avenue \\ Cambridge, MA 02138 \\ May 2021
}

For their helpful comments and suggestions, we thank Elsa Allman, Zahi Ben-David, Rebecca De Simone, Dave Denis, Scott Guensey, Jon Karpoff, Ed Rice, Philip Strahan, Ren Stulz, and Michael Weisbach, as well as brownbag, seminar, and conferences participants at Ohio State University, University of Washington, University of Tennessee, the Young Scholars Finance Consortium, and the Financial Markets and Corporate Governance Conference. We are also very grateful to Reza Noorani and Victor Yu at the Mine Safety and Health Administration for gracefully answering our many data requests and questions. Hoa Briscoe-Tran provided excellent research assistance. The views expressed herein are those of the authors and do not necessarily reflect the views of the National Bureau of Economic Research.

NBER working papers are circulated for discussion and comment purposes. They have not been peer-reviewed or been subject to the review by the NBER Board of Directors that accompanies official NBER publications.

(C) 2021 by Erik P. Gilje and Michael D. Wittry. All rights reserved. Short sections of text, not to exceed two paragraphs, may be quoted without explicit permission provided that full credit, including $\odot$ notice, is given to the source. 
Is Public Equity Deadly? Evidence from Workplace Safety and Productivity Tradeoffs in the Coal Industry

Erik P. Gilje and Michael D. Wittry

NBER Working Paper No. 28798

May 2021

JEL No. G30,G32,G34,J24,J38

\begin{abstract}
We study how ownership structure, in particular public listing status, affects workplace safety and productivity tradeoffs. Theory offers competing hypotheses on how listing related frictions affect these tradeoffs. We exploit detailed asset-level data in the U.S. coal industry and find that workplace safety deteriorates dramatically under public firm ownership, primarily in mines that experience the largest productivity increases. We find evidence consistent with information asymmetry between managers and shareholders of public firms, and ties of private firm ownership with local communities being first-order drivers of workplace safety and productivity tradeoffs.
\end{abstract}

Erik P. Gilje

The Wharton School

University of Pennsylvania

3620 Locust Walk

Philadelphia, PA 19104

and NBER

gilje@wharton.upenn.edu

Michael D. Wittry

The Ohio State Univeristy

854 Fisher Hall

2100 Neil Ave

854 Fisher Hall

Columbus, OH 43210

United States

wittry.2@osu.edu 
How does ownership structure affect workplace safety and firm productivity? Privately held and publicly traded firms are responsible for roughly equal portions of U.S. economic output, but are subject to extremely large differences in agency and financial frictions, which can lead to significant variation in corporate policies and real outcomes (Gilje and Taillard, 2016). While extant literature has explored economic mechanisms that affect workplace safety (Cohn and Wardlaw, 2016; Cohn et al., 2021b) and firm productivity (Bai et al., 2018), evidence on how ownership structure affects these outcomes and potential tradeoffs is limited. In this paper, we focus on one dimension of distinct variation in ownership structure, public listing status, and study how listing related frictions affect potential tradeoffs that firms face between workplace safety and firm productivity.

Theory offers competing predictions on how listing status might relate to workplace safety. The cost of adverse workplace incidents could be higher for public companies, which have greater disclosure requirements (Christensen et al., 2017), and are subject to greater stockholder and political pressure. Moreover, public firms could have higher reputational risk than private firms due to greater media exposure and awareness (Chen et al., 2004). Finally, public firms have greater access to external capital markets (Brav, 2009), potentially alleviating cuts to safety investments when internally constrained (Cohn and Wardlaw, 2016). These factors each point towards public firms having safer workplaces than their private counterparts.

Alternatively, there are reasons to believe that privately held companies could have fewer workplace injuries and accidents. For example, due to information asymmetry arising from diffuse ownership, public firm managers may face additional pressure to cut costs on workplace safety to increase profits. Relatedly, private firms may have non-diversified owners with strong social ties to a local community, and may derive personal utility from a safe workplace and good relationships with employees. Lastly, the greater dispersion of ownership in public firms leads to greater risk-sharing opportunities among shareholders (Pagano, 1993; Pagano et al., 1998), which may manifest in additional safety risk. These factors would suggest that public firms engage in activities that result in a higher workplace injury and accident propensity. Ultimately, it is an empirical question as to how workplace safety changes with listing status, as well as what tradeoffs a firm makes as it relates to safety and productivity. 
We focus on coal mining in the U.S. Due to the inherent safety concerns, this industry receives significant scrutiny from Federal authorities over workplace safety practices. Safety violation, injury and accident, and fatality data is collected and reported in a standardized way across all public and private firms for almost four decades. The data also offer detailed granularity on the number of hours worked, number of employees, and amount of coal produced at the asset/facility level. Moreover, the data also provide information on the type of workplace risk the regulators attach to a specific violation; that is, whether the behavior in question was related to a low-, medium-, or high-probability activity. Lastly, while we do not have an instrument for listing status, we are able to trace individual asset ownership that moves across listing status, and thus structure empirical tests to mitigate the most salient endogeneity concerns.

We find that workplace safety is strongly related to listing status. Specifically, mines that are purchased by public firms or are part of an IPO experience a large increase in safety violations. However, this increase is concentrated in what appears to be tail risk, or violations for potential accidents stemming from low-probability events. Such violations increase by nearly $57 \%$. Furthermore, upon a listing status change, workplace fatalities increase four-fold relative to the unconditional sample mean. These results are directionally consistent with the hypotheses that link public listing status with workplaces that are less safe and engaged in higher risk taking. Importantly, these results allow us to characterize not only the direction, but also the type of safety risk that public firms undertake. In particular, we find no evidence that public firms are reckless or participate in the highest probability activities. Rather, public firms tend to increase risk by augmenting their distribution to include significantly more low-probability events, which at times results in fatal accidents.

We also find that mine productivity is tightly linked with listing status. That is, mines that become publicly held experience a significant increase in the productivity of their labor. Specifically, coal production per hour spent on mining activities increases by $13.2 \%$ and coal production per mine employee goes up 15.8\%. Assuming fixed wages and hours across a listing status change, this would translate into nearly a $\$ 3.19$ million annual profit increase for the average mine in our sample. How do these changes in productivity relate to changes in 
workplace risk and safety? We assess this directly by splitting our sample by the relative size of productivity increases over the life of the asset. We find that increases in safety violations upon a listing status change are concentrated in the group of mines that have experienced the largest productivity increases. This evidence suggests that public firms increase labor productivity at the expense of workplace safety within individual mines, and more specifically, that firms are increasing safety risks in parts of the distribution that are expected to be lower probability, and therefore likely to be realized less frequently.

Why might managers of public firms be more willing to trade off worker safety for increased productivity? We assess several non-mutually exclusive economic mechanisms that may be driving the change in behavior among publicly listed firms. Specifically, we construct empirical tests to assess support for whether information asymmetry between public shareholders and public firm managers could be associated with our results. We also examine empirical evidence on how private firm ownership and local presence and ties with the community amongst private firms may be related to our results. We are careful to note that this list of mechanisms is not exhaustive, but rather, these are the set of mechanisms most conducive to being tested in our setting.

Extant literature has argued that information asymmetry between shareholders and managers creates difficulty for shareholders in observing managerial effort relative to potential confounding factors (Bertrand and Mullainathan, 2001; Grenadier and Malenko, 2011). To assess to what extent this channel might be driving our results, we exploit changes in coal prices that are likely to differentially alter the importance of information asymmetry for public firms relative to private firms. Coal price shocks have several attractive features. First, they are plausibly exogenous to any single mine or firm. Secondly, just as in the oil and gas industry, coal price declines have a disproportionately large impact on firm profitability, which in turn strongly impacts managerial turnover (Jenter and Lewellen, 2020).

At privately held firms, where there is a tight link between ownership and control, owners are likely to know to what extent poor firm performance can be attributed to "bad luck" with prices. Alternatively, at public firms, the separation of ownership and control likely makes it difficult for owners to know what portion of poor performance can be attributed to price 
changes, and what portion is due to poor managerial skill or decision-making (Bertrand and Mullainathan, 2001). Further, problematic CEOs at public firms are unlikely to be successful when attempting to signal these portions to diffuse shareholders (Grenadier and Malenko, 2011). Thus, during periods of coal price declines, managers of public firms may feel intense pressure to increase productivity, and thus take on risks that they think are unlikely to materialize in order to do so. In re-estimating our tests on workplace safety and productivity, we find that the entirety of the effects are concentrated during years in which coal prices are declining, precisely when the separation of ownership and control is likely to exert its greatest pressure on managerial decision-making.

We also construct two sets of tests to assess how private firm preferences and community ties may relate to our results. First, firm managers and owners may feel a stronger responsibility to the local community surrounding the mine if they reside nearby (e.g., if the firm's offices are headquartered in close proximity to the mine). Public firms, on the other hand, have diffuse ownership and thus may have less consumption value related to stewardship of jobs located close to a firm's headquarters. We find that public listing status is only related to workplace safety and productivity for mines that are located near the firm's headquarters. This result is consistent with privately held mines being safer in communities close to where a firm's owners and managers live, and then transitioning to being more dangerous, but more productive workplaces, once owned by a dispersed set of public owners.

Secondly, to assess further support for this channel, we also examine the role of regulatory oversight of mines. If private firm managers do indeed derive significant consumption value from being good stewards of safety for their employees, the intensity of regulatory oversight and the probability of violation detection may ultimately play a small role in the safetyproductivity tradeoff optimization. To test this hypothesis, we exploit a small number of MSHA inspection office closures, moves, and district realignments that change the proximity of the regulator to assigned mines, and thus the intensity of oversight and probability of detection. Because MSHA inspection office locations are chosen to optimize inspector travel times to all of the operating mines in the district, these changes are plausibly exogenous to any given mine or firm. We find that mines do re-optimize the mix between workplace 
safety and productivity following inspection office changes, but only among those held by publicly-listed firms. In particular, publicly owned mines significantly increase both lowand medium-probability safety violations, as well as productivity, following large decreases in the proximity to the regulator, which is consistent with the argument that regulatory oversight is potentially less important for closely-held firms that may have stronger ties to their employee's well-being.

A potential concern with our empirical design is that listing status is not randomly assigned, and that private and public firms differ across a range of both observable and unobservable characteristics. Fortunately, our data allow us to observe behavior at the mine level, and our primary results focus on within mine ownership changes across public and private firms. This allows us to control for many of the most salient endogeneity concerns. For example, focusing on the asset level holds constant the type of coal being mined (mine cash flow and investment opportunities), the specific technology employed to mine the coal (surface versus underground), the organic safety features of the mine (natural ventilation systems), and the mine size and resources/reserves available, among other things. We also verify directly in placebo tests that mine safety and productivity are not trending prior to the ownership change. Additionally, each mine makes up only a portion of the entire portfolio of company assets, and on its own, is unlikely to drive a listing status change or acquisition decision. Finally, the subsample comparisons we make when evaluating economic mechanisms would require a confounding, non-listing status related effect, to reconcile why the observed differences across subsamples would be present.

This study contributes to a large literature on listing status, and more broadly, on the ownership structure of the firm. Existing papers have studied how listing related frictions affect dividends (Michaely and Roberts, 2012), capital structure (Brav, 2009), investment (Gilje and Taillard, 2016; Asker et al., 2011), research and development (Bernstein, 2015), and pollution (Shive and Foster, 2020). These papers highlight various economic mechanisms related to listing status that affect differences in firm behavior, including frictions in accessing external capital, as well as information asymmetry between mangers and shareholders. Our paper also more broadly highlights the role that information asymmetry plays across own- 
ership structures, and relates to theories on myopia (Stein, 1989), and signaling to investors (Grenadier and Malenko, 2011).

We also contribute to the literature that relates the economic frictions firms face to employee well-being. For example, Hanka (1998) draws a link between firm debt levels and reductions in employment, while Benmelech et al. (2015) show that firms with higher leverage have employment levels that are more sensitive to cash flow changes. Whiles these studies highlight an indirect link to employee well-being through their employment status, Cohn and Wardlaw (2016) point out a more direct link. In particular, Americans experience 3.5 million workplace injuries a year, with estimated costs to the economy of $\$ 250$ billion annually. Both Cohn and Wardlaw (2016) and Filer and Golbe (2003) find that the financial condition of the firm significantly impacts workplace safety environments.

Two prior studies are closely related to our work in this area. The first is Cohn et al. (2021b), who find that workplace safety improves upon the private equity buyout of a publicly traded firm. This result is directionally consistent with ours, but the authors are unable to observe the potential tradeoffs between safety and productivity in their sample. The second is Christensen et al. (2017), who find that workplace safety improves and labor productivity decreases for mines owned by SEC-registered issuers following Dodd Frank's requirement that mine safety records be included in financial reports. Our work complements and extends these results by showing public firms appear to bear more safety risk, even with higher costs of disclosure.

Lastly, we contribute to a greater understanding of factors that drive productivity. Extant literature has studied an abundance of economic mechanisms which might drive productivity (see Foster et al. (2001) for a review). Recent finance literature has tied aggregate productivity to financing frictions (Bai et al., 2018). Overall, our paper extends each of these branches of the literature by linking ownership structure, and in particular, listing relatedfrictions to tradeoffs between workplace safety and employee well-being, firm risk-taking, and productivity. 


\section{Data, Empirical Measures of Workplace Safety, and Summary Statistics}

\subsection{Data}

The vast majority of our data are collected by the Mine Safety and Health Administration (MSHA). Part 50 of Title 30 of the Code of Federal Regulation (30 CFR Part 50) requires operators to file reports with MSHA pertaining to accidents, occupational injuries and illnesses, safety violations and civil penalties, coal dust samples, as well as employment and coal production data, all at the mine level. Further, MSHA keeps detailed historical records of mine addresses and geographic coordinates, MSHA inspection offices assignments, mine production status, unionization status, mine operators and contractors, and ultimate mine ownership (what MSHA calls controllers).

MSHA provides most of the $30 \mathrm{CFR}$ Part 50 data in text delimited data sets as part of an Open Government Initiative. This data is often recompiled and reproduced by various other federal entities. For example, for ease of access, the National Institute for Occupational Safety and Health (NIOSH) posts annual address/employment and accident/injury/illness files in SPSS format through the Center for Disease Control and Prevention (CDC) website. ${ }^{1}$ The remaining data are accessible through MSHA's Mine Data Retrieval System (MDRS). The MDRS includes additional text delimited data on dust and noise samples, civil penalties and safety violations, and conferences on contested citations.

Though much of the data MSHA collects covers both coal and metal/nonmetal mining, we focus exclusively on coal mining for a few reasons. First, and foremost, 30 CFR Part 50 requires coal operators to file reports to MSHA on production quantities, while the same is not required of metal/nonmetal operators. Secondly, on average, coal mining is more

\footnotetext{
${ }^{1}$ See https://www.cdc.gov/niosh/mining/data/default.html.
} 
dangerous than metal/nonmetal mining, creating a more suitable laboratory for studying the safety tradeoffs public and private firms make. ${ }^{2}$

We combine the mine-level data from MSHA with hand-collected data on listing status for a mine's ultimate owner. We collect this data from a number of sources, including firm SEC filings accessed via EDGAR, CRSP, CapitalIQ, and data on IPO dates from Jay Ritter's website. Because of complex corporate trees with multiple levels of subsidiaries, this is a non-trivial collection task. However, when possible, we cross-validate listing statuses using multiple data sources. Finally, average annual coal sale price data by state and by mine type (underground or surface) are from the U.S. Energy Information Administration (EIA). The EIA makes this data publicly available through the Annual Coal Report Archive dating back to $1993 .^{3}$

We impose several data filters on our main sample. First, we winsorize all ratio variables at the 1st and 99th percentiles. Definitions for all variables used in our main analysis appear in Appendix Table A.1. Second, for a mine-year observation to be included in our sample, it must satisfy the following criteria: (1) the mine is actively producing coal and employs at least 5 workers, (2) the mine produces bituminous (not anthracite) coal, and (3) the ultimate owner of the mine is not foreign, not part of a joint venture, not structured as a sole proprietorship or a partnership, and owns at least one other mine (two mines total). These filters leave a final sample of 4,257 coal mines owned by 1,411 ultimate parents (68 that are public at some point) for a total of 21,538 mine-firm-year observations. Figure 1 displays the geographic location of the mines in our final sample. Though they are overwhelmingly located in the Mid-Atlantic, there is little evidence of clustering by listing status.

\section{$1.2 \quad$ Empirical Measures of Workplace Safety}

Investigating the relationship between ownership structure, particularly private versus public firms, and workplace safety is inherently difficult. The data needed to address this relation-

\footnotetext{
${ }^{2}$ Though increased regulations have made them safer over time, both coal mining and metal/nonmetal mining remain among the most dangerous industries in the world. However, according to MSHA, since 1983, the average fatality rate per 100,000 miners in coal mining is nearly double that of metal/nonmetal mining.

${ }^{3}$ See https://www.eia.gov/coal/annual/archive/.
} 
ship are often unavailable, particularly for private firms. Further, even when the data are accessible by researchers, for example through OSHA, studies can suffer from small samples, infrequent sampling, and significant heterogeneity in types and severity of workplace incidents, e.g. across different industries. Also complicating empirical studies of workplace safety is the fact that most empirical measures are from an ex post perspective. While realized accidents are almost certainly positively correlated with ex ante workplace safety investments and risk-taking, accidents and workplace incidents have a large random component and using only realized measures could lead to mistaken inferences. Finally, it is difficult to find measures that reflect tangible safety costs to the firm. That is, the costs associated with missed time, medical bills, and workers compensation, etc., for small injuries such as sprains and contusions are likely negligible to the firm.

To make progress on each of these data challenges, we proxy for a firm's workplace safety with two empirical measures. The first is from an ex-ante perspective - the number of safety violations MSHA cites a firm for potential accidents. This measure is similar to that of Filer and Golbe (2003) and Cohn et al. (2021b), who use OSHA safety violations, and is distinct from many studies on workplace safety such as Cohn and Wardlaw (2016) in that the firm may or may not actually experience an accident or injuries stemming from a specific violation. However, unlike OSHA violations which stem from infrequent and irregular inspections, safety violations in coal mining arise from regular inspections by MSHA, which is mandated by Section 103(a) of the Federal Mine Safety and Health Act of 1977 to inspect underground mines a minimum of four times per year and surface mines a minimum of twice per year. ${ }^{4}$ Further highlighting the unique nature and richness of the data, MSHA classifies the violations into categories based on the likelihood or probability an accident will ultimately occur. ${ }^{5}$ We use this variation to further homogenize the type and severity

\footnotetext{
${ }^{4}$ MSHA also notes that mines with high levels of explosives or toxic gases will be inspected even more frequently, and that inspections are also conducted following complaints of unsafe working conditions.

${ }^{5}$ MSHA deems these categories "unlikely," "reasonably likely," and "highly likely," while we refer to these categories as "low probability," "medium probability," and "high probability." While investigators aren't directed to classify the violations by specific percentages, MSHA notes that "the occurrence of an injury or illness does not have to be more probable than not in order for the likelihood to be designated as reasonably likely." Furthermore, MSHA classifies each violation into four categories based on the severity of the potential
} 
of workplace incidents, and to more precisely examine the types and amount of safety risk public and private firms are willing or able to bear.

Figure 2 displays the annual time series of total coal mining safety violations issued by MSHA from 1993-2018. Through the Act of 1977 and the MINER Act of 2006, mining in general, and coal mining specifically, has undoubted become safer though time (e.g., see Nieto and Duerksen (2008) and Amoako et al. (2020)). However, the trend in aggregate safety violations suggests a procyclical enforcement of these regulations. That is, both in our sample and in all of MSHA's data, safety violations peek in the run-up to the dot-com bubble and the financial crisis in 2000 and 2008, respectively, before declining through the recessions. The share of violations between public and private firms in our sample remains relatively stable through time. Notwithstanding, our sample accounts for approximately $25 \%$ of the total safety violations in the coal mining industry each year.

Second, to supplement our main results using ex ante safety violations, we also exploit an ex-post measure of realized workplace safety - the number of mining fatalities a firm reports to MSHA each year. Even with a significant random component in workplace fatalities, this measure offers a significant benefit in measuring the quality of a firm's workplace safety. Principally, fatalities are likely to represent the single largest cost to mining firms stemming from underinvestment in workplace safety, or for bearing additional safety risk. Thus, while simple injury propensities may also correlated with the firm's safety environment, fatalities seem to be a more appropriate measure in disentangling the costs and benefits of safety risk.

Figure 3 displays the annual trend in coal mining fatalities in the U.S. Unlike safety violations, aggregate fatalities have been nearly monotonically decreasing since the early 80 s, save for large accidents such as the Upper Big Branch Mining disaster that tragically killed 29 miners in $2010 .{ }^{6}$ However, the decline in fatalities is concentrated in private firms, whether through actual safety improvements or a reduction in private firms through conglomeration. The annual number of fatalities in public firms, on the other hand, has remained relatively accident, "no lost work days," "lost work days," "permanently disabling," and "fatal." For more information on these classifications, see Watkins (2020).

${ }^{6}$ The Upper Big Branch Disaster does not appear in our sample as MSHA listed the mine as a joint venture between Massey Energy and Hanson PLC. 
stable over our sample period. In total, our sample represents upwards of $50 \%$ of the total coal mining fatalities in the U.S. each year.

\subsection{Summary Statistics}

Table 1 displays the summary statistics for the main sample. Panel A reports the distributions for mine-year observations. The observations for safety violations reflect a sample period of 1993-2018, while those of fatalities, production and employment reflect a sample period of 1985-2018. ${ }^{7}$ There is significant dispersion in the distribution for each variable. For example, while a number of mine-year observations have no safety violations, the maximum suggests a single mine received nearly 1,400 violations in one year. The average (medium) mine in our sample is cited for just over 42 (10) safety violations each year, with nearly all being classified as having a low or medium probability of the accident ultimately occurring. Furthermore, even with the imminent dangers in coal mining, fatalities are still quite rare, occurring at a rate of only 0.022 deaths per year. Other safety characteristics such as injuries, work days missed due to injuries, and fines each suggest relatively safe median mines, with violations and accidents concentrated in the most dangerous mines. For example, while the median mine pays safety violation fines of only $\$ 2,300$ each year, the most ardent violators pay fines in excess of $\$ 3$ million.

Panel A also reports that the average (median) mine produces just over $700,000(150,000)$ tons of clean coal each year. With the range of average coal sale prices reported by the U.S. EIA over our sample period, the average (median) mine likely grosses in the range of $\$ 10$ to $\$ 50$ million ( $\$ 4.5$ to $\$ 10$ million) in revenue each year, depending on the time period. 60 mine workers account for over 125,000 employee hours at the average mine, producing coal at an average rate of 7,500 tons per employee, or almost 4 tons per employee hour. Finally,

\footnotetext{
${ }^{7}$ Strictly speaking, accident and production data is reported starting in 1983, and safety violations data also extends back to the early-to-mid 1980s. However, there appear to be anomalies in the early parts of the data. For example, the number of safety violations issued through 1992 is nearly negligible. In speaking with MSHA representatives, we focus on sample periods starting in 1985 for fatalities and production, and 1993 for safety violations to to ensure the highest quality of data in our empirical tests. However, we ensure our results are qualitatively similar if we utilize the full sample of data.
} 
$22 \%$ of the mine-year observations in our main sample represent mines that are ultimately owed by a public firm.

Panel B displays mine-year observations aggregated to the firm-year level. By and large, the firm-year distributions mimic the mine-year distributions. The average firm in our sample is cited for just under 100 safety violations each year, with the firm's workplace safety environment leading to an average fatality rate of 0.045 , as well as 9 injuries, nearly two years of lost work days due to those injuries, and fines of nearly $\$ 120,000$ each year. The average firm employs 124 mine workers and produces almost 1.5 million tons of coal each year across 10 different mines. ${ }^{8}$ Finally, reflecting the fact that public firms own more mines than private firms on average, the percentage of firm-year observations representing public ownership is far less than mine-year observations at only $7 \%$.

\section{Main Results}

In this section, we analyze whether a firm's listing status affects its workplace safety environment. We begin by exploring the univariate differences between privately- and publicly-held mines. Table 2 reports these results. From simple two-sample mean comparison t-tests, it is clear that mines owned by public firms are much different than those owned by private firms. Publicly-owned mines have more safety safety violations, fatalities, injuries, days missed, and fines. However, publicly-owned mines are also much bigger in scale, producing more coal and employing more workers. Thus, from the simple mean comparisons, it is difficult to draw strong conclusions about the relationship between listing status and workplace safety.

Table 2 also reports univariate differences after including the full set of fixed effects employed in our multivariate analysi \maketitles below. That is, Diff after FE reports the differences between publicly and privately held mines after including year, mine, county of mine location, and ultimate parent fixed effects. Further, the differences in safety violations

\footnotetext{
${ }^{8}$ Relative to previous studies focusing on the mining industry, the firms in our sample oversee more, but smaller, mines. For example, both Moel and Tufano (2002) and Wittry (2021) report that the average firm owns around three mines. These differences likely reflect heterogeneity in scale and scope across different commodities.
} 
also include MSHA inspection office (district) fixed effects. Finally, for these differences, we cluster our standard errors at the ultimate parent level. The univariate differences in this setting point to a much clearer economic relationship. The difference in total safety violations and low-probability safety violations become even bigger with the fixed effects and remain significant at the $5 \%$ level, even with clustered standard errors. However, medium- and highprobability safety violations, injuries, and fines paid all become insignificantly different in the publicly and privately held samples. This gives us confidence that our fixed effects are soaking up relevant variation in our dependent variables of interest that is not attributable to listing status.

Further, the scale of operations differences between publicly and privately held mines become nearly statistically indistinguishable after adding fixed effects. The difference in production quantities remains marginally significant at the $10 \%$ level, however, the differences in the number of employees and the total employee hours are insignificant. Finally, the differences in productivity, as measured by tons of coal produced per employee or per employee hour, remain significant. Overall, Table 2 suggests publicly and privately held mines have significantly different levels of safety violations, fatalities, and productivity.

\subsection{Safety Violations}

Our first set of multivariate results focus on a firm's ex ante workplace safety environment. Specifically, our dependent variable for these tests is the natural log of one plus the number of safety violations that a firm is cited for in a given year. ${ }^{9}$ Further, we use MSHA's classification of accident likelihood to separate the dependent variable into low-, medium-, and high-probability safety violations. Our sample period is 1993 through 2018. We include an exhaustive series of fixed effects to control for unobservable heterogeneity that may impact

\footnotetext{
${ }^{9}$ In a recent working paper, Cohn et al. (2021a) point out potential issues with the "LOG1PLUS" specification. In the Internet Appendix, Table IA.1, we report several additional specifications, including ones that normalize violations by the number of inspections, the number of employee-hours, and the number of employees. Each of these specifications produce results that are qualitatively and quantitatively similar to the main results reported below, suggesting our setting is largely free of the problems discussed in their paper. Similarly, in the Internet Appendix, we ensure the results for labor productivity in Table 5 are not sensitive to the log (LOLS) specification. Where possible, we continue to report specifications with logged dependent variables to facilitate simple interpretation of the coefficients.
} 
listing status and workplace safety simultaneously. In particular, each of our specifications includes year, mine, county of mine location, inspection office, and ultimate parent fixed effects. The combination of specifying our empirical tests at the mine-year level and employing this set of fixed effects should rule out the most salient endogeneity concerns. For example, mine fixed effects holds constant the type of coal being mined (mine cash flow and investment opportunities), the specific technology employed to mine the coal (surface versus underground), the organic safety features of the mine (natural ventilation systems), and the mine size and resources/reserves available. Further, with ultimate parent fixed effects, our identification arises from firm IPOs or going-private transactions, and from the acquisition of privately-held mines or private mining firms, rather than from cross-sectional differences between public and private firms.

Figure 4 displays the prevalence of each of these listing status changes throughout the sample period. While many listing status changes cluster in a handful of years with large IPOs (e.g., CONSOL Energy and ICG) and acquisitions of large private firms (e.g., ICG's acquisition of Horizon Natural Resources), there is significant variation in listing statuses in other years as well, with nearly two-thirds of the sample years showing changes in listing status for at least 25 mines. Finally, we cluster standard errors at the ultimate parent level to account for serial autocorrelation across different mines owned by the same firm. Formally, our regressions take the following form:

$$
\begin{aligned}
\log \left(1+\text { SafetyViolations }_{i s t}\right)= & \alpha+\beta_{1} \text { PublicOwner }_{i s t}+ \\
& \beta_{2} X_{i s t}+\text { YearF } E_{t}+{\text { MineF } E_{i}+\text { CountyF }_{i}+} \\
& \text { InspectionOfficeF } E_{i}+\text { UltimateParentF }_{s}+\varepsilon_{i s t}
\end{aligned}
$$

The unit of observation is mine $i$ owned by firm $s$ at time $t$.

Table 3 reports the results. Column (1) displays the results without additional control variables $\left(X_{i s t}\right)$. The coefficient on Public owner is 0.346 and is marginally significant at the $10 \%$ level. This suggests that mines that are purchased by public firms or are part of an IPO 
experience a $41 \%$ increase in safety violations. ${ }^{10}$ This result is directionally consistent with the hypotheses that link public listing status with workplaces that are less safe.

Columns (2) adds the following additional control variables: log of total production of clean coal, log of the average number of mine employees, log of the total employee hours worked in the mine, log of total mines owned by the ultimate parent, the age the mine's operator ultimate parent, and an indicator variable equal to one if the mine is unionized. All variables are defined in Appendix Table A.1. Unlike the fixed effects, these covariates account for time-variant observable characteristics at the mine or firm level. For example, total production, the number of employees, total employee hours worked account for the scale of operations at the mine level. Further, the number of mines owned by the ultimate parent is a measure of overall firm size. Each of these control variables is meant to soak up variation in the annual number of safety violations attributed to a change in listing status, when a change in safety violations may be due to changes in operational scale at the mine or firm level. Reflecting this possibility, the coefficient on Public owner becomes smaller in magnitude and statistically insignificant in Column (2), while the coefficients on $\log ($ Production) and $\log ($ Hours $)$ are positive and significant at the $1 \%$ level.

The results in Columns (1) and (2) suggest an economic relationship between a firm's public listing status and its workplace safety environment. However, these results do not reflect a consistent statistically significant effect. One potential explanation for the lack of robustness across different specifications is heterogeneity within safety violations. That is, the level of safety risk is not homogeneous and varies across listing status in such a way that the fixed effects do not capture the relationship. To address this potential measurement issue, in Columns (3) through (8), we split the LHS variable into three categories based on the MSHA-assigned likelihood of an accident occurring from a specific safety violation. While the classification of violations into the low-, medium-, and high-probability categories

\footnotetext{
${ }^{10}$ Though log-level linear regression coefficients are often interpreted as the exact percentage change in the dependent variable, the coefficients actually represent an approximation of this change. Unfortunately, this approximation get worse as the effect size increases. For example, in Column (1), the coefficient on Public owner is 0.346 and rough interpretation is that a listing status change leads to a $35 \%$ increase in safety violations. However, the exact percentage change can be calculated as $(\exp (0.346)-1) \times 100=41.3 \%$. Throughout the paper, we use the exact percentage change when discussing to economic magnitudes.
} 
is subjective (the MSHA investigator has final discretion), the inspection office fixed effects should capture variation from differences in level of enforcement and discrepancies in the way each investigator classifies a violation. Further, our results are robust to including inspection office by year fixed effects.

Columns (3) and (4) report models in which the dependent variables are the number of annual safety violations stemming from activities that MSHA classifies as low-probability. Columns (5) and (6) and Columns (7) and (8) report models in which the dependent variables are the number of medium-probability and high-probability safety violations, respectively. The magnitude of a public listing status's impact on safety violations is monotonically decreasing in the probability the violations lead to an accident. For example, the coefficients on Public owner in Columns (3) and (4), in which the dependent variable is low-probability safety violations, are both large, and significantly different than zero at least at the $5 \%$ level. Furthermore, the results are economically significant, as the coefficient in Column (4) suggests at $57 \%$ increase in low-probability violations upon a listing status change. The coefficients on Public owner in Columns (5) through (8), on the other hand, are significantly smaller. In fact, public listing status appears to be negatively correlated with high-probability safety violations, though the coefficients are not significant.

These results suggest public firms are significantly more likely to take on additional safety risk, however, only risks that are least likely to ultimately manifest as accidents. In particular, there is no evidence to suggest that public firms are negligent relative to their private counterparts, but rather, the results point to a level of safety risk among publicly-listed firms that is calculated. Nevertheless, Internet Appendix Table IA.2 shows the additional tail risk significantly endangers employees, as the largest differences between public and private firms concentrate in the violations with the most severe likely outcomes as deemed by MSHA. In sum, it appears public firms increase their safety risk by augmenting their distribution to include more low-probability activities.

The trends for each classification of safety violations (all, low-, medium-, and highprobability) surrounding a listing status change appear in Figure 5. We estimate the annual coefficients of Public owner in each subfigure using the related full specification in Table 3. 
Each subfigure shows the slightest increase in safety violations during year $t=-2$ for soonto-be-public mines relative to private mines. However, in each, this increase is not significant. Furthermore, in Panels (a) through (c), the level of safety violations actually decreases from year $t=-2$ to year $t=-1$. Figure 5 reinforces the results of Table 3 in that only lowprobability safety violations jump upon the acquisition of a private mine by a public acquirer or through a change in listing status due to an IPO. Moreover, the effect is quite persistent and even increasing through time. Finally, Figure 5 eases concerns of simultaneity or reverse causality bias as the upward movement in safety violations occurs only after a listing status change.

\section{$2.2 \quad$ Fatalities}

Next, we investigate whether listing status is related to the realization of the workplace safety risks public firms appear to take from the previous section. That is, our next set of results focuses on our ex post measure of workplace safety - the number of fatalities a mine reports

each year. Because public firms appear to only bear additional safety risk in the category of violations that stem from low-probability activities, it is not immediately obvious that this would manifest as realized workplace safety costs through fatal accidents. We use nearly the same set of fixed effects as in Section 2.1; however, because MSHA has no avenue to be subjective with fatalities, we omit the inspection office fixed effects. Finally, we continue to cluster our standard errors at the ultimate parent level. Formally, our regression is:

$$
\begin{aligned}
& \text { TotalFatalities }_{i s t}=\alpha+\beta_{1} \text { PublicOwner }_{i s t} \\
& \beta_{2} X_{i s t}+\text { YearF } E_{t}+\text { MineF } E_{i}+ \\
& \text { CountyF } E_{i}+\text { UltimateParentF } E_{s}+\varepsilon_{i s t}
\end{aligned}
$$

Table 4 reports the results. Columns (1) through (2) present results from specifications that focus on all fatalities, including those that stem from large mining accidents. To ensure such mining disasters are not driving the main result for public firms, Columns (3) and (4) focus only on fatalities that stem from single-miner accidents. The results across all 
specifications for fatalities are consistent - public listing status is positively and significantly correlated with the level of fatal accidents. For example, the coefficient on Public owner in Column (2), which includes the full set of control variables, is 0.097 and is significant at the $5 \%$ level. This suggests that mines that are acquired by a public owner or experience an IPO realize a $440 \%$ increase in fatalities relative to the unconditional sample mean. The results when using only fatalities from single-miner accidents remain largely unchanged. The coefficient on Public owner in Column (4) is 0.059 and is statistically significant at the $1 \%$ level, reflecting a $330 \%$ increase from the unconditional sample mean. ${ }^{11}$

The control variables in Columns (2) and (4) are the same as those used in Table 3 and are, for the most part, insignificant. Unlike safety violations, which were most impacted by the production level and the number of employee hours, fatalities are most strongly linked to the total number of employees working in the mine. This result differs from findings from the early 1980s that show smaller (by number of employees) mines have higher fatality rates (The President's Commission on Coal, 1980; National Research Council, 1982; Neumann and Nelson, 1982). However, these studies predate our sample and the discrepancy likely suggests that safety standards have improved differentially at smaller mines, whether through technological advances or increased regulation (e.g., through the 1977 Act). The coefficient on ultimate parent age is negative, suggesting workplace safety improves (or safety risk decreases) as a mine's ultimate parent ages. This could be consistent with decreasing levels of information asymmetry between ownership and control as firms age, and thus, less myopia on the part of managers. Finally, the coefficient on the indicator variable for union status is negative and statistically significant in Column (2). Thus, unions appear to create mines with safer working conditions than non-unionized mines.

Figure 6 displays the trend in fatalities surrounding a listing status change. We estimate the annual coefficients of Public owner using the same specification as Column (2) in Table 4. The difference in the number of deaths at about-to-be publicly-held mines relative to continued privately-held mines is near zero and insignificant in the years leading up to the

\footnotetext{
${ }^{11}$ Internet Appendix Table IA.3 verifies that the results are robust to alternative specifications, such as fatalities normalized by employee-hours of the number of employees.
} 
listing status change, and immediately increases at time 0. Furthermore, the effect appears to increase through time. The coefficient on the indicator for year $t \geq 3$ is over 0.11 and significant at the $1 \%$ level. The lack of pre-trend is inconsistent with public firms acquiring relatively more risky mines or owners of riskier mines having a higher probability of going public. Overall the results of this section suggest that, while public firms only take additional safety risk that is unlikely to be realized, these actions do indeed lead to significant costs through the increased likelihood of fatal accidents.

\subsection{Tradeoff Between Safety and Productivity}

Why would public firms take on additional safety risk? On the one hand, there is some evidence that firms, particularly mining firms, make tradeoffs between productivity and workplace safety. For example, Neumann and Nelson (1982) find the Coal Mine Health and Safety Act of 1969 led to marginally lower aggregate fatality rates in the 1970s. The authors also find, however, that this period was marked by significantly lower production per man hour. Christensen et al. (2017) show workplace safety improves and labor productivity decreases for mines owned by SEC-registered issuers following Dodd Frank's requirement that mine safety records be included in financial reports. Each of these studies presents evidence consistent with a tradeoff between safety and productivity, and each is consistent with the argument that the optimal number of workplace injuries and fatalities is not zero for many firms (e.g., see Kamiya et al. (2020)).

On the other hand, the negative relationship between productivity and workplace safety is not conclusive in the extant literature. For example, Sider (1983) finds that many factors, not just heightened safety, led to decreased productivity following the 1969 Act. Further, National Research Council (1982), Grayson (2001), and Asfaw et al. (2013) each find that "a productive mine is a safe mine," that is, productivity is negatively correlated with the incidence of occupational injuries. However, each of these studies measures productivity differently, and even Asfaw et al. (2013) note that this relationship is highly sensitive to the 
addition of control variables. Furthermore, none of these studies examine the tradeoff within a mine or even within firm.

We begin our analysis of this potential tradeoff for public firms by simply examining the relationship between listing status and labor productivity. We follow the same identification strategy as in Section 2, specifying our regressions at the mine-year level, and include the same series of fixed effects and clustered standard errors as in Table 4. We measure labor productivity in two ways, tons of clean coal produced per employee hour spent on mining activities, and tons of clean coal produced per mine employee. We take the log of each of these ratios to mitigate the influence of outliers, however as Internet Appendix Table IA.4 shows, our results are robust to simply using the winsorized ratios. Our sample period is 1985 through 2018.

Table 5 reports the results using both measures of productivity. The coefficients on Public owner across all four specifications are positive and statistically significant at the $5 \%$ level. That is, regardless of how we define productivity (tons per employee-hour or tons per employee) and how we specify our model (e.g., the inclusion of control variables), publiclyheld mines produce more coal per hour or employee than privately-held mines. The economic magnitude of the increase is also highly significant. Upon being acquired by a public firm or upon its ultimate owner's IPO, a mine increases its clean coal production per employee-hour by $13.2 \%$ and its clean coal production per employee by nearly $16 \%$.

Figure 7 displays the relative trend in productivity surrounding a listing status change. Productivity in soon-to-be publicly-held mines appears flat relative to continued privatelyheld mines in the year prior to a listing status change and remains near zero in the year of the change. However, this differential jumps sharply the year after the mine becomes publiclyheld and remains significantly higher through time. Figure 7 suggests that the increase in labor productivity happens with a delay relative to the deterioration in workplace safety.

The results in Table 5 and Figure 7, on their own, do not show a direct tradeoff public firms may make regarding safety and productivity. For example, public firms may be more advanced in allocating resources and safety investment to mines with better technology - both production and safety. Thus, upon an acquisition of new mines or through an IPO, public 
firms exacerbate a division between the mines they own - those that have low productivity and are dangerous, and those that have high productivity and are safe.

To better distinguish between a productivity-safety tradeoff and alternative mechanisms, we re-estimate our models after splitting our sample into mines that enjoy large productivity gains over their life, and those that experience small or negative productivity gains over their life. We define the productivity gain as tons of coal produced per employee hour averaged over the last five years of a mine's productive life, minus tons of coal produced per employee hour averaged over the first five years a mine's productive life. Then, we construct an indicator variable for large productivity gains that is equal to one if the mine's productivity gain is in the upper tertile, and zero if it is in the lower two tertiles. ${ }^{12}$

Table 6 reports the results from this subsample analysis. The results provide clear evidence for the direct tradeoff mechanism. Publicly-held mines are cited for more safety violations than privately-held mines, but only in mines that enjoy large productivity gains over their life. The economic magnitude of this differential between publicly- and privatelyheld mines is extremely large, with mines increasing all safety violations and low-probability violations by $70 \%$ and $136 \%$, respectively, upon acquisition or IPO in the large productivity gain sample. Furthermore, the difference in the coefficients on Public owner in the two samples are significantly different from each other at the $1 \%$ level for all and low-probability safety violations, and at the $5 \%$ level for medium-probability safety violations. We find no significant effects for high-probability safety violations in Columns (7) and (8). These results suggest that public firms tend to increase safety risk by augmenting their distribution to include lower-probability events, which at times results in fatal accidents, while realizing higher levels of coal production per employee hour. ${ }^{13}$

\footnotetext{
${ }^{12}$ Our results are robust to alternative ways of defining productive mines and large productivity gains.

${ }^{13}$ For the subsample splits in this table, and those in Section 3, we focus on safety violations rather than on fatalities. The main reason for this is that fatalities are a very low probability event with a large random component, and splitting the data may exacerbate issues with making inferences from such events. Nonetheless, in Internet Appendix Table IA.5, we report subsample splits for fatalities and several other measures of workplace safety, including explosions, fines, and coal dust concentration. The results are similar to those that we report in the main tables. Specifically, significant results for variables are generally concentrated in the subgroup of interest, and at times, are significantly different from the other subgroup.
} 
To get a rough idea of the dollar amount of this tradeoff for publicly held mines, we perform a simple back-of-the-envelope calculation. Assuming hourly wages across private and public firms are largely equivalent, a 13.2\% increase in hourly productivity corresponds to a $\$ 3.19$ million gross profit increase for the average mine in our sample. ${ }^{14}$ Of course, even if wages are constant across listing status, this increase in productivity is not costless for public firms. Indeed, we have already shown public firms bear significantly more safety risk to realize higher productivity. One crude way to summarize the expected increase in costs of this safety risk is through the financial market reaction to news of a fatal accident. To the extent that such accidents reveal information not only about the specific incident, but also about the latent safety environment at the mine, one can view the stock price reaction as a measure of the total costs to the firm for bearing safety risk.

Focusing on the public firms in our sample, we are able to match the news of 215 fatal accidents to securities price data and calculate cumulative abnormal returns (CARs) upon their announcement (which in each case coincides with the day of the accident). The mean $(0,10)$ day CAR using a market-model is $-1.41 \%$, and is significant at the $1 \%$ level (see Internet Appendix Table IA.7). Multiplying the (0,10) day abnormal returns for each firmaccident pair by the market capitalization from time $t$-1 suggests an average dollar loss of $\$ 31.57$ million per fatal accident. The coefficient in Column (2) from Table 4 indicates public firms experience 0.097 additional fatalities per year, thus carrying an expected additional annual cost of $\$ 31.57 \times 0.097=\$ 3.06$ million. In sum, it appears that public firms, on average, increase safety risk right up to the point in which the marginal costs swamp the marginal benefits.

\footnotetext{
${ }^{14}$ We arrive at $\$ 3.19$ million by taking the average total production across our sample $(710,268$ tons of clean coal) and multiplying by the $13.2 \%$ increase in productivity. If the number of employee-hours remain constant surrounding a listing status change (Internet Appendix Table IA.6 suggests they do), this gives us the total increase in coal production due to the change in listing status - 93,755 tons of coal. Then to get the dollar amount of the increase, we take this number multiplied by the average sales price per ton in our sample $(\$ 34.00)$. E.g., $710,268 \times 0.132 \times 34.00=3,187,683$.
} 


\section{Economic Channel}

In this section, we examine two, non-mutually exclusive, economic channels for our main results: the role of information asymmetry, and that of private firm preferences and owners' and managers' ties to the local community. There are, of course, more possibilities than the ones we test. For example, a substitution of inputs from labor to more productive, but more dangerous, capital among less financially-constrained public firms could contribute to higher production per unit of labor but also more dangerous workplace environments. ${ }^{15}$ However, our data are most conducive to testing these two particular channels regarding information asymmetry and local ties. The rest of this section discusses each of these channels in turn.

\subsection{The Role of Information Asymmetry}

Several prominent papers have argued that the separation of ownership and control can create information-related agency costs because diffuse owners have trouble observing managerial effort relative to potential confounding factors such as negative price shocks (Bertrand and Mullainathan, 2001), and because managers have difficulty signaling the true reasons for performance declines to shareholders (Grenadier and Malenko, 2011). Because of this, managers of public firms may face stronger pressure to prop up profitability at high costs, particularly during market-induced industry shocks, as there is a strong relationship between firm performance and forced CEO turnover (Huson et al., 2001; Peters and Wagner, 2014; Jenter and Lewellen, 2020) that is exacerbated by the separation of ownership and control (Denis et al., 1997). CEO succession dynamics in the coal industry further magnifies this pressure on managers. For example, because coal firms tend to be rather homogeneous, executive replacement costs are likely low, and thus forced turnover events will tend to be more frequent (Parrino, 1997). Moreover, in niche industries such as coal, CEO's outside options are likely to be limited (Liu, 2014).

\footnotetext{
${ }^{15}$ Inconsistent with this mechanism, Internet Appendix Table IA.6 shows no change in labor utilization surrounding a listing status change.
} 
To assess the role of information asymmetry in our setting, we follow in the spirit of Bertrand and Mullainathan (2001) and focus on periods of declining coal prices. Specifically, we hypothesize that managers face more pressure to increase productivity at the expense of safety when (1) there is a larger separation between ownership and control (e.g. at public firms), and (2) when ownership has more difficulty discerning whether a drop in profitability is due to bad managerial performance or simply due to bad luck (e.g. a drop in coal prices). The use of year-over-year (YOY) changes in coal prices offers several advantages. First, as (Bertrand and Mullainathan, 2001) note, commodity price changes are plausibly exogenous to any one manager or firm. ${ }^{16}$ Second, though aggregate U.S. coal prices are relatively smooth year-to-year (e.g., see Figure 8, Panel A), there is significant time-series and cross-sectional variation in coal prices by both state and mine-type (surface vs. underground). Figure 8, Panel B highlights this heterogeneity. In each year of our sample period, there are both price increases and decreases in the U.S. coal market. Further, the cross-sectional dispersion in YOY changes can be quite large. For example, in 2001, the spread between the largest price increase (Texas surface mining at $44.4 \%$ ) and the largest price decrease (Ohio underground mining at $-57.7 \%$ ) was $102 \%$. Finally, just as with crude oil, coal price fluctuations tend to have large effects on firm performance.

We use the average coal sale price changes from the EIA to split the main sample into mine-year observations that experience a price increase and those that experience a price decrease relative to the year prior. Due to the EIA sale price data availability back to 1993, our sample periods for safety violation and productivity are each 1993-2018. Table 7 displays the results from our models re-estimated over each subsample.

Panel A of Table 7 reports results for safety violations, while Panel B reports the results for both measures of labor productivity. Columns (1) and (2) in Panel A show the impact of public listing status on the overall amount of safety violations cited to a mine during

\footnotetext{
${ }^{16}$ Consistent with this, we find no support that coal prices are related to acquisition or IPO decisions. Further, Internet Appendix Table IA.8 shows the results of a placebo price shock design that is akin to testing for parallel trends in the coal price analysis. In particular, we construct empirical tests that use price shocks from two years prior (rather than the contemporaneous year), and find no significant differences among results on public firm ownership for workplace safety or productivity.
} 
years of price increases and price decreases. While a change in listing status did not have a significant affect on overall safety violations in our main results, it does appear to impact overall safety violations in years and locations that experience a decline in coal prices. The coefficient Public owner in Column (2) is large (0.470) and significant at the 5\% level,. Further, the coefficient is significantly different from that in Column (1) at the 1\% level. These results indicate varying levels of workplace safety risk between public and private firms across different market conditions.

Consistent with earlier results, the increase in safety violations among publicly-listed firms is concentrated in violations attached to lower probability events. The coefficient on Public owner in Column (4) is significant at the $1 \%$ and is nearly five times as large as the coefficient in Column (3), a difference that is also significant at the $1 \%$ level. We further document that there are no statistically significant results among the medium- and high-probability safety violations in either subsample in Columns (5) through (8), thought the coefficients for medium-probability safety violations are significantly different from each other at the $5 \%$ level

Panel B of Table 7 focuses on the other half of the tradeoff: productivity. The results are strongly supportive of managers focusing on productivity and profitability over workplace safety during periods in which agency concerns are heightened. That is, both measures of productivity suggest large and significant increases upon a listing status change, but only during years of price declines. Both subsample splits reflect a difference in coefficients on Public owner that is significant at the 5\% level. Overall, the results in Table 7 reflect a larger willingness for public managers to engage in a productivity for workplace safety tradeoff during periods exacerbating information asymmetry.

\subsection{The Role of Private Firm Preferences and Local Community Ties}

Next, we design two sets of empirical tests to assess the importance of private firm preferences and potential social and local community ties on the part of owners and managers. Both 
focus on the mine's geographic location relative to important stakeholders of the firm: the local community in which private firm managers and owners are likely to reside, and the regulators tasked with overseeing a mine's workplace safety environment.

\subsubsection{Mine Proximity to Firm Headquarters}

How does the local community surrounding firm operations impact tradeoffs between safety and productivity? Private firm owners and managers may feel a stronger responsibility to employee safety if a mine is located in close proximity to where they reside. Public firms, on the other hand, have diffuse ownership and thus may have less consumption value related to stewardship of jobs in the community. We use the location of the ultimate parent's headquarters as a proxy for the location in which firm managers and owners are likely to have social ties and capital.

MSHA provides the geographic coordinates of each mine in our sample, as well as the city of headquarters for roughtly $80 \%$ of our main sample. We use the longitude and latitude of the mine, and those of the center of each headquarter city to calculate the distance in miles between the mine and headquarters. Next, we split our sample into two subgroups based on this distance. To be specific, we define a mine to be located far from its ultimate parent's headquarters if it is in the top tertile of the distance distribution, and near if it is in the bottom two tertiles. The top tertile corresponds to a distance of 105 miles as the crow flies. While 105 miles may not seem like an incredibly tight proximity, it is significantly lower than the average distance between plants and headquarters reported in Giroud (2013). However, we verify that our results are not sensitive to this exact mileage split.

Table 8 reports the results from this subsample analysis. Panel A focuses on safety violations and Panel B on productivity. Panel A continues to show a significant relationship between public listing status and safety violations. However, the relationship is concentrated only in mines that are located near the firm headquarters. This is true even of medium- and high-probability safety violations, to an extent. Further, consistent with our earlier results for highly productive mines and years during coal price declines, the magnitude of the effect 
of public listing status on low-probability safety violations is significantly different in the two subgroups.

Panel B shows similar results for productivity. In both measures, public listing status is significantly related to an increase in coal production per employee-hour or employee, but only in the subset of mines that are located in close proximity to the firm's headquarters. Yet again, both F-stats indicate that the effects across subsamples are significantly different. While the proximity of a mine to its headquarter and public listing status are endogenously determined, these results are strongly suggestive of differences in preferences regarding the safety and well-being among private and public firms, particularly as it relates to managers' and owners' standing in the local community.

\subsubsection{Regulator Oversight and Probability of Detection}

As a second test of private firm preferences and local community ties, we focus on the monitoring intensity of the regulator (MSHA) and the probability of being caught violating safety protocols. In particular, if private firm managers and owners value the safety of their employees and maintaining reputational capital in their local communities, regulatory oversight may play a smaller role in optimizing the workplace safety and productivity tradeoff than it does for publicly held firms, which have more diffuse ownership. Once again, we use the geographic coordinates of the mines in our sample, as well as the cities of the inspection offices assigned to each mine, to calculate the distance in miles between the mine and the regulator. We focus on this distance as a proxy for the level of regulatory oversight and the probability of violation detection. Specifically, we assume that monitoring intensity, and thus the probability of detection, is increasing in the mine's proximity to the inspection office.

In order to identify changes in a mine's monitoring intensity, we take advantage of a small number of mines that are reassigned to different inspection office locations due to office closures, moves, or entire district realignments. In speaking with MSHA representatives, these changes stem from the objective to optimize inspector travel times to and from all the producing mines in the inspection district. In our sample, the median inspection office covers 
26 mines each year. ${ }^{17}$ Thus, we argue that these changes are plausibly exogenous to any one given mine in each district. We further analyze this assumption in Section 4.2.

Figure 9 displays examples of two such inspection office changes. Panel A displays the creation of a new inspection office in Longview, Texas in 2013, while Panel B reflects the phasing out of an inspection office in Jasper, Alabama in the late 1990s and early 2000s, before closing permanently in 2003. In both cases, several of the mines in our sample experienced large changes in their proximity to the assigned inspection office. However, in both cases, there is significant heterogeneity in the size and direction of the treatment effect. For example, while most of the mines in Panel A experienced a decrease in proximity to the inspector, one mine (represented by the green dot) experienced a significant increase in proximity following the new office in Longview. Further, though all of the proximities in Panel B decreased, only three experienced a distance increase of greater than 60 miles (the rough equivalent of a two-hour round-trip commute to inspect a mine).

We exploit this variation in the treatment for MSHA office changes to identify plausibly exogenous changes in the intensity of regulatory oversight and the probability of violation detection. In particular, we define a variable, $M S H A$ proximity change, that is equal to 1 if an inspection office change induces an increase in the distance between the mine and the inspector of at least 60 miles, -1 if the change decreases the distance by at least 60 miles, and 0 if the change is under 60 miles or if there is no change at all. Sixty miles is admittedly ad hoc, but represents a change in total travel time for the inspector of roughly two hours, and as such, is likely to create meaningful change in the regulatory oversight of the mine. Internet Appendix Table IA.9 analyzes different classifications for the size of the change and shows similar results.

We use this change variable as part of a difference-in-differences framework. Specifically, we interact the MSHA proximity change variable with post, which is equal to 1 the year of, and

\footnotetext{
${ }^{17}$ Due to the data filters we impose, tis is almost certainly a minimum bound on the number of mines in each inspection district.
} 
all the years following a change, and 0 otherwise. ${ }^{18}$ Further, to capture any differential effects for public and private firms, we also include the triple interaction term MSHA proximity change $\times$ post $\times$ public owner. Table 10 reports the results. Consistent with regulatory oversight impacting incentives, mines that experience a proximity change of at least 60 miles do seem to re-optimize the safety-productivity tradeoff. However, the effect is completely concentrated in mines owned by public firms. To be specific, publicly held mines significantly increase both safety violations (low- and medium-probability) and productivity following a decrease in the mine's proximity to the inspection office. These results are consistent with those in Section 3.2.1 and suggest private firms have different underlying preferences regarding employee's well-being.

\section{Robustness, Endogeneity and Extensions}

The results in Sections 2 and 3 support the hypothesis that public firms place a larger focus on productivity and profitability than private firms, but do so at the cost of providing their employees a safe workplace. This section explores the robustness of these findings to prominent endogeneity concerns. We also briefly discuss an extension of our results to a different dimension of variation in ownership structure. Finally, the Internet Appendix considers a number of other potential concerns. For example, Section I of the IA considers whether our findings are simply an IPO effect by restricting the analysis to a sample of matched private-to-public and private-to-private acquisitions.

\subsection{Placebo Test for the Main Results}

Through our identification strategy (models specified at the asset level with high dimensional fixed effects), we rule out many of the most salient endogeneity concerns. Further, the nature of our cross-sectional analysis, particularly coal price shocks and MSHA inspection

\footnotetext{
${ }^{18} \mathrm{~A}$ few mines experience multiple changes, or the bouncing back and forth between inspection offices. In these cases, we focus only on sustained changes (those of two years or more), and the first change for any mine. That is we discard all observations after a second change for those mines.
} 
office changes, significantly raise the bar in finding reasonable alternative interpretations. Even still, the relationships we report in the paper are correlations. That is, we cannot definitively conclude that public listing status causes increased safety violations, fatalities, or productivity. Rather, our setting could be plagued with reverse causality issues and we could be documenting the fact that riskier firms with more dangerous mines go-public, and public firms tend to acquire more dangerous, yet more productive mines.

To mitigate concerns of reverse causality, we re-estimate our regressions in the spirit of Figures 5 through 7, but with more empirical structure placed on the pre-period. We define a new indicator variable, Placebo $_{i s t}$ that takes a value of one if $t=-2$ or $t=-1$ in eventtime. That is, Placebo equals one in the two years prior to a firm's IPO or acquisition of a privately-held mine in our main sample, or in the two years prior to an acquisition in our matched-sample acquisition analysis. Table 11 reports the results. Each column soundly rejects the argument that reverse causality is driving our results. In each model we reestimate, the coefficient on Placebo is statistically insignificant. Further, in most models, the magnitude of the coefficient is very to close to zero, and is even negative in many of the models.

\subsection{Predictors of MSHA Inspection Office Changes}

In Section 3.2.2, we argue that MSHA inspection office changes are plausibly exogenous to any one given mine because MSHA attempts to optimize travel times across all operating mines in the district. It could be the case, however, that these changes are systematically related to public firm ownership or covered mine's safety environment and resulting productivity. Such a systematic relationship has the potential to change the interpretation of our findings regarding regulatory oversight and the probability of detection. For example, one salient concern is that MSHA inspection offices change location in response to covered mines safety records or public listing status.

To investigate to what extent this may be a problem in our setting, we examine what factors predict the timing of MSHA office moves for individual mines. In particular, we 
create an indicator variable equal to one if mine $i$ experiences a change in its assigned MSHA inspection office during year $t$. We discard all observations for mines that switch offices after the year of the change and compare the switch year to all mine-year observations that have no such change after the year 1993 over a range of model specifications.

Table 12 displays the results. Consistent with MSHA's stated objective to optimize inspector travel times over all the producing mines in a district, Columns (1) through (3) show that the number of producing mines and the average distance between the inspection office and these mines at time $t$ are significant predictors of an inspection office change at time $t+1$. However, even these variables become statistically significant as we add inspection office and ultimate parents fixed effects. Further, and most importantly, we see almost no mine or firm level characteristics predict changes in inspection offices. The only variable that consistently predicts a change is the number of employees at a given mine. Even so, employment appears to be equally related to both moves that decrease the mine's proximity to the inspector and those that increase it, and thus creates little concern for our identification in Section 3.2.2.

\subsection{Extension to Sole Proprietorship and Partnerships}

The empirical tests in our main results focus on the difference between publicly and privately held corporations, and as such, are most informative about this specific variation in ownership structure. It is, however, reasonable to wonder how our results extend to other dimensions of variation in ownership structure. For example, there is likely to be a spectrum of willingness or ability to trade off safety risk for productivity within private firms. On the one the end of that spectrum, firms with a diverse group of private equity investors may behave similar to publicly listed firms. On the other, family or founder firms may take on significantly less risk than even the average closely-held private firm.

Unfortunately, we do not have data on private equity holdings or the holdings of the founder. We do, however, have information on company type for the firms in our sample that are the current owners of the mines (as of the end of 2018). That is, MSHA provides time- 
invariant descriptions of the firms as "Corporations," "Partnerships," "Sole Proprietors," or "Other." Internet Appendix Table IA.11 reports results from empirical specifications that focus on only private firms, and focus on an indicator variable equal to 1 if a firm's company type is defined as a sole proprietorship or a partnership. Because this indicator does not vary through time, we are unable to include ultimate parent fixed effects. Rather, using the remaining set of fixed effects, these tests focus on the variation in workplace safety and productivity when a mine switches owners from a corporation to a sole prop./partnership or vice versa. Consistent with the finding that the safety-productivity tradeoff is less pronounced among private firms relative to public firms, sole proprietorship and partnerships appear to bear significantly less safety risk, but also realize lower productivity.

\section{Conclusion}

Private firms comprise a large portion of the U.S. economy, and are subject to different economic frictions than public firms. We show that differences in these economic frictions are relevant for both workplace safety risk-taking and productivity. We go a step further and document that it appears that firms trade off productivity and workplace safety in ways that suggest such tradeoffs are driven by information asymmetry between managers and shareholders of public firms, and ties of private firm ownership to local communities.. Non-shareholder stakeholders, such as employees, have become an important focus in the literature, this paper highlights important tradeoffs between workplace safety and productivity that public firms engage in relative to private firms. 


\section{References}

Amoako, R., Buaba, J., Brickey, A., 2020. Identifying risk factors from MSHA accidents and injury data using logistic regression. Mining, Metallurgy \& Exploration .

Asfaw, A., Mark, C., Pana-Cryan, R., 2013. Profitability and occupational injuries in u.s. undergound coal mines. Accident Analysis and Prevention 50, 778-786.

Asker, J., Farre-Mensa, J., Ljungqvist, A., 2011. Comparing the investment behavior of public and private firms. NBER Working Paper No. 17394.

Bai, J., Carvalho, D., Phillips, G.M., 2018. The impact of bank credit on labor reallocation and aggregate industry productivity. Journal of Finance 73, 2787-2836.

Benmelech, E., Bergman, N., Seru, A., 2015. Financing labor. Working Paper .

Bernstein, S., 2015. Does going public affect innovation? Journal of Finance 70, 1365-1403.

Bertrand, M., Mullainathan, S., 2001. Are CEOs rewarded for luck? The ones without principals are. Quarterly Journal of Economics 116, 901-932.

Brav, O., 2009. Access to capital, capital structure, and the funding of the firm. Journal of Finance 64, 263-308.

Chen, H., Noronha, G., Singal, V., 2004. The price response to S\&P 500 index additions and deletions: Evidence of asymmetry and a new explanation. Journal of Finance 59, 1901-1930.

Christensen, H.B., Floyd, E., Liu, L.Y., Maffet, M., 2017. The real effects of mandated information on social responsibility in financial reports: Evidence from mine-safety records. Journal of Accounting and Economics 64, 284-304.

Cohn, J., Liu, Z., Wardlaw, M., 2021a. Count data in finance, Woring paper.

Cohn, J., Nestoriak, N., Wardlaw, M., 2021b. Private equity buyouts and workplace safety. Review of Financial Studies, Forthcoming.

Cohn, J.B., Wardlaw, M.I., 2016. Financing constraints and workplace safety. Journal of Finance 71, 2017-2058.

Denis, D.J., Denis, D.K., Sarin, A., 1997. Ownership structure and top executive turnover. Journal of Financial Economics 45, 193-221.

Filer, R.K., Golbe, D.L., 2003. Debt, operating margin, and investment in workplace safety. Journal of Industrial Economics 51, 359-381.

Foster, L., Haltiwanger, J.C., Krizan, C.J., 2001. New development in productivity analysis. University of Chicago Press , 303-372. 
Gilje, E., Taillard, J., 2016. Do public firms invest differently than private firms? Taking cues from the natural gas industry. Journal of Finance 71, 1733-1778.

Giroud, X., 2013. Proximity and investment: Evidence from plant-level data. Quarterly Journal of Economcis 128, 861-915.

Grayson, R.L., 2001. Safety vs... productivity and other factors in US underground coal mines. Mining Engineering .

Grenadier, S.R., Malenko, A., 2011. Real options signaling games with applications to corporate finance. Review of Financial Studies 24, 3993-4036.

Hanka, G., 1998. Debt and the terms of employment. Journal of Financial Economics 48, $245-282$.

Huson, M.R., Parrino, R., Starks, L.T., 2001. Internal monitoring mechanisms and CEO turnover: A long-term perspective. Journal of Finance 56, 2265-2297.

Jenter, D., Lewellen, K., 2020. Performance-induced ceo turnover. Review of Financial Studies, Forthcoming.

Kamiya, S., Kang, J.K., Kim, J., Milidonis, A., Stulz, R.M., 2020. Risk management, firm reputation, and the impact of successful cyberattacks on target firms. Journal of Financial Economics, Forthcoming.

Liu, Y., 2014. Outside options and CEO turnover: The network effect. Journal of Corporate Finance 28, 201-217.

Michaely, R., Roberts, M., 2012. Corporate dividend policies: Lessons from private firms. Review of Financ 25, 711-746.

Moel, A., Tufano, P., 2002. When are real options exercised? An empirical study of mine closings. Review of Financial Studies 15, 35-64.

National Research Council, 1982. Toward Safer Undground Coal Mines. National Academy Press, Washington, D.C.

Neumann, G.R., Nelson, J.P., 1982. Safety regulation and firm size: Effects of the coal mine health and safety act of 1969. Journal of Law \& Economics 25, 183-199.

Nieto, A., Duerksen, A., 2008. The effects of mine safety legislation on mining technology in the USA. International Journal of Mining and Mineral Engineering 1, 95-103.

Pagano, M., 1993. The flotation of companies on the stock market: A coordination failure model. European Economic Review 37, 1101-1125.

Pagano, M., Panetta, F., Zingales, L., 1998. Why do companies go public? An empirical analysis. Journal of Finance 53, 27-64. 
Parrino, R., 1997. CEO turnover and outside succession: A cross-sectional analysis. Journal of Financial Economics 46, 165-197.

Peters, F.S., Wagner, A.F., 2014. The executive turnover risk premium. Journal of Finance 69, 1529-1563.

Shive, S.A., Foster, M.M., 2020. Corporate governance and pollution externalities of public and private firms. Review of Financial Studies 3, 1296-1330.

Sider, H., 1983. Safety and production in underground coal mining. Review of Economics and Statistics 65, 225-233.

Stein, J.C., 1989. Efficient capital markets, inefficient firms: A model of myopic corporate behavior. Quarterly Journal of Economics 104, 655-669.

The President's Commission on Coal, 1980. Recommendations and Summary Findings. U.S. Government Printing Office, Washington, D.C.

Watkins, T.R., 2020. Citation and order writing handbook number PH20-I-3.

Wittry, M.D., 2021. (Debt) overhang: Evidence from resource extraction. Review of Financial Studies, Forthcoming. 


\section{Table 1: Summary Statistics}

This table reports summary statistics for all publicly- and privately-owned U.S. coal mines over a sample period of 1985 through 2018 . A mine-year observation is included in our sample if it satisfies the following requirements: (1) the mine is actively producing coal and employs at least 5 workers, (2) the mine produces bituminous (not anthracite) coal, and (3) the owner of the mine is not foreign, not part of a joint venture, not structured as a sole proprietorship or a partnership, and owns at least one other mine. Panel A reports the summary statistics for mine-year observations, and Panel B reports the summary statistics for firm-year observations. All variable definitions appear in Appendix Table A.1. Data on mining accidents, fatalities, safety violations, production, and employment, as well as ultimate mine ownership and mining acquisitions, are from the Mine Safety and Health Administration (MSHA) published through an Open Government Initiative. Data on listing status are hand-collected from firm filings, CRSP, CapitalIQ, and data on IPO dates from Jay Ritter's website.

\begin{tabular}{|c|c|c|c|c|c|c|c|c|}
\hline & Obs. & Mean & SD & $\mathrm{P} 0$ & $\mathrm{P} 25$ & $\mathrm{P} 50$ & P75 & P100 \\
\hline \multicolumn{9}{|c|}{ Panel A: Mine-year observations } \\
\hline \multicolumn{9}{|l|}{ Safety and risk measures } \\
\hline Total saftey violations & 12,173 & 42 & 96 & 0 & 2 & 10 & 34 & 1,395 \\
\hline Low probability violations & 12.173 & 24 & 64 & 0 & 0 & 4 & 16 & 945 \\
\hline Medium probability violations & 12,173 & 17 & 38 & 0 & 1 & 5 & 16 & 511 \\
\hline High probability violiations & 12,173 & 0.4 & 1.5 & 0 & 0 & 0 & 0 & 50 \\
\hline Total fatalities & 21,538 & 0.022 & 0.186 & 0 & 0 & 0 & 0 & 13 \\
\hline Total fatalities (single miner accidents) & 21,538 & 0.019 & 0.147 & 0 & 0 & 0 & 0 & 8 \\
\hline Injuries & 21,538 & 4.5 & 11.5 & 0 & 0 & 1 & 4 & 313 \\
\hline Days missed due to injury & 21,538 & 379.4 & 1477.2 & 0 & 0 & 10 & 138 & 79,692 \\
\hline Days missed per injury & 21,538 & 61.1 & 362.4 & 0 & 0 & 0 & 31 & 6,332 \\
\hline Fines paid $(\$ s)$ & 7,969 & 44,998 & 161,250 & 0 & 434 & 2,300 & 14,438 & $3,245,842$ \\
\hline \multicolumn{9}{|l|}{ Production, employment, and efficiency } \\
\hline Tons of clean coal produced & 21,538 & 710,268 & $3,182,063$ & 20 & 53,746 & 150,353 & 433,190 & $116,225,536$ \\
\hline Number of employees & 21.538 & 60 & 103 & 5 & 13 & 25 & 52 & 1.620 \\
\hline Number of employee hours & 21,538 & 127,545 & 229,322 & 83 & 19,713 & 47,511 & 116,867 & $3,347,772$ \\
\hline Tons of clean coal per employee & 21,538 & 7,430 & 6,020 & 2 & 3,462 & 5,931 & 9,524 & 33,235 \\
\hline Tons of clean coal per employee hour & 21,538 & 3.90 & 3.21 & 0.00 & 2.14 & 3.13 & 4.60 & 24.34 \\
\hline \multicolumn{9}{|l|}{ Ownership } \\
\hline Public owner (\%) & 21,538 & 0.22 & & & & & & \\
\hline
\end{tabular}


Table 1 -continued

\begin{tabular}{|c|c|c|c|c|c|c|c|c|}
\hline & Obs. & Mean & $\mathrm{SD}$ & $\mathrm{P} 0$ & $\mathrm{P} 25$ & $\mathrm{P} 50$ & P75 & P100 \\
\hline \multicolumn{9}{|l|}{ Panel B: Firm-year observations } \\
\hline \multicolumn{9}{|l|}{ Safety and risk measures } \\
\hline Total saftey violations & 5,474 & 93.7 & 383.9 & 0 & 2 & 11 & 40 & 6,293 \\
\hline Low probability violations & 5,474 & 53.7 & 243.9 & 0 & 0 & 4 & 17 & 3,889 \\
\hline Low probability violations & 5,474 & 38.9 & 152.0 & 0 & 1 & 6 & 21 & 3,092 \\
\hline High probability violiations & 5,474 & 0.8 & 3.7 & 0 & 0 & 0 & 0 & 81 \\
\hline Total fatalities & 10,471 & 0.045 & 0.291 & 0 & 0 & 0 & 0 & 13 \\
\hline Total fatalities (single miner accidents) & 10,471 & 0.038 & 0.233 & 0 & 0 & 0 & 0 & 8 \\
\hline Days missed due to injury & 10,471 & 780.4 & 3346.5 & 0 & 0 & 7 & 137 & 89,766 \\
\hline Days missed per injury & 5,310 & 123.4 & 529.0 & 0 & 10 & 28 & 60 & 6,300 \\
\hline Fines paid $(\$ s)$ & 3,046 & 117,363 & 632,471 & 0 & 478 & 2,342 & 15,264 & $13,343,763$ \\
\hline \multicolumn{9}{|l|}{ Production, employment, and efficiency } \\
\hline Tons of clean coal produced & 10,471 & $1,460,964$ & $6,710,895$ & 20 & 50,402 & 135,709 & 418,810 & $130,485,480$ \\
\hline Number of employees & 10,471 & 124 & 423 & 5 & 12 & 25 & 59 & 7,145 \\
\hline Number of employee hours & 10,471 & 262,350 & 940,487 & 88 & 19,111 & 45,170 & 120,507 & $15,998,981$ \\
\hline Tons of clean coal per employee & 10,471 & 6,840 & 5,403 & 294 & 3,393 & 5,524 & 8,684 & 32,817 \\
\hline Tons of clean coal per employee hour & 10,471 & 3.63 & 2.47 & 0.57 & 2.13 & 3.00 & 4.33 & 16.28 \\
\hline Public owner (\%) & 10,471 & 0.07 & & & & & & \\
\hline
\end{tabular}


Table 2: Univariate Differences: Public vs. Private

This table reports univariate differences between publicly- and privately-owned U.S. coal mines over a sample period of 1985 through 2018 . Panel A reports the univariate differences for mine-year observations, first reporting simple two-sample t-test differences and p-values. Secondly, this panel reports differences after including year, mine, county of mine location, and ultimate parent fixed effects (the safety violations differences also include inspection office fixed effects). Th is is the same set of fixed effects included in our multivariate regressions below. Further matching our main analysis, standard errors for the differences are clustered at the ultimate parent level. All variable definitions appear in Appendix Table A.1. Data on mining accidents, fatalities, safety violations, production, and employment, as well as ultimate mine ownership and mining acquisitions, are from the Mine Safety and Health Administration (MSHA) published through an Open Government Initiative. Data on listing status are hand-collected from firm filings, CRSP, CapitalIQ, and data on IPO dates from Jay Ritter's website. *, **, and *** denote significance at the $10 \%, 5 \%$, and $1 \%$ level, respectively.

\begin{tabular}{|c|c|c|c|c|c|c|c|c|}
\hline & \multicolumn{2}{|c|}{ Public owner } & \multicolumn{2}{|c|}{ Private owner } & \multirow[b]{2}{*}{ Difference } & \multirow[b]{2}{*}{ p-Value } & \multirow[b]{2}{*}{ Diff after FE } & \multirow[b]{2}{*}{ p-Value } \\
\hline & Obs. & Mean & Obs. & Mean & & & & \\
\hline \multicolumn{9}{|l|}{ Panel A: Mine-level differences } \\
\hline \multicolumn{9}{|l|}{ Safety and risk measures } \\
\hline Low probability violations & 3,161 & 54.5 & 9,012 & 13.5 & 41.0 & 0.000 & 83.9 & 0.020 \\
\hline Medium probability violations & 3,161 & 33.7 & 9,012 & 11.7 & 22.0 & 0.000 & 23.2 & 0.162 \\
\hline High probability violiations & 3,161 & 0.6 & 9,012 & 0.3 & 0.3 & 0.000 & -0.5 & 0.676 \\
\hline Total fatalities & 4,779 & 0.044 & 16,759 & 0.016 & 0.028 & 0.000 & 0.096 & 0.018 \\
\hline Total fatalities (single miner accidents) & 4,779 & 0.036 & 16,759 & 0.014 & 0.022 & 0.000 & 0.060 & 0.004 \\
\hline Days missed due to injury & 4,779 & 800.3 & 16,759 & 259.4 & 540.9 & 0.000 & 709.7 & 0.060 \\
\hline Days missed per injury & 4,779 & 83.7 & 16,759 & 54.7 & 29.0 & 0.000 & 83.3 & 0.000 \\
\hline Fines paid $(\$ s)$ & 2,312 & 103,138 & 5,657 & 21,236 & 81,902 & 0.000 & $-7,083$ & 0.695 \\
\hline \multicolumn{9}{|l|}{ Production, employment, and efficiency } \\
\hline Tons of clean coal produced & 4,779 & $1,995,576$ & 16,759 & 343,749 & $1,651,827$ & 0.000 & 727,030 & 0.072 \\
\hline Number of employees & 4,779 & 137 & 16,759 & 38 & 99 & 0.000 & 27 & 0.438 \\
\hline Number of employee hours & 4,779 & 297,967 & 16,759 & 78,948 & 219,019 & 0.000 & 79,240 & 0.249 \\
\hline Tons of clean coal per employee & 4,779 & 9,889 & 16,759 & 6,728 & 3,160 & 0.000 & 1,182 & 0.005 \\
\hline Tons of clean coal per employee hour & 4,779 & 5.0 & 16,759 & 3.6 & 1.4 & 0.000 & 0.6 & 0.004 \\
\hline
\end{tabular}




\section{Table 3: Listing Status and Mine-Level Safety Violations}

This table reports the results of linear regression models in which the dependent variable is the natural log of one plus the number of safety violations at mine $i$, owned by ultimate parent $s$, during year $t$. The sample consists of publicly- and privately-owned U.S. coal mines over a sample period of 1993 through 2018 . The independent variable of interest is Public owner ist. In Columns (5) through (10), the safety violations for constructing the dependent variables are split by the probability of an accident actually occurring, as deemed by the Mine Safety and Health Administration (MSHA) at the time of the citation for the safety violation. All variable definitions appear in Appendix Table A.1. Data on mining safety violations, production, and employment, as well as ultimate mine ownership and mining acquisitions, are from the Mine Safety and Health Administration published through an Open Government Initiative. Data on listing status are hand-collected from firm filings, CRSP, CapitalIQ, and data on IPO dates from Jay Ritter's website. Robust standard errors, clustered at the firm level, are reported in parentheses. ${ }^{*},{ }^{* *}$, and ${ }^{* * *}$ denote significance at the $10 \%, 5 \%$, and $1 \%$ level, respectively.

\begin{tabular}{|c|c|c|c|c|c|c|c|c|}
\hline \multirow{3}{*}{$\begin{array}{l}\text { Dependent variable }= \\
\text { MSHA Prob. of Accident }=\end{array}$} & \multicolumn{8}{|c|}{$\log \left(1+\right.$ safety violations $\left._{i s t}\right)$} \\
\hline & \multicolumn{2}{|c|}{ All } & \multicolumn{2}{|c|}{ Low } & \multicolumn{2}{|c|}{ Med. } & \multicolumn{2}{|c|}{ High } \\
\hline & $(1)$ & $(2)$ & $(3)$ & $(4)$ & $(5)$ & $(6)$ & $(7)$ & $(8)$ \\
\hline Public owner $_{i s t}$ & $\begin{array}{l}0.346^{*} \\
(0.195)\end{array}$ & $\begin{array}{c}0.235 \\
(0.169)\end{array}$ & $\begin{array}{c}0.529^{* * *} \\
(0.183)\end{array}$ & $\begin{array}{c}0.449^{* *} \\
(0.175)\end{array}$ & $\begin{array}{c}0.278 \\
(0.197)\end{array}$ & $\begin{array}{c}0.182 \\
(0.173)\end{array}$ & $\begin{array}{l}-0.010 \\
(0.172)\end{array}$ & $\begin{array}{l}-0.019 \\
(0.168)\end{array}$ \\
\hline $\log \left(\right.$ Production $\left._{\text {ist }}\right)$ & & $\begin{array}{c}0.127^{* * *} * \\
(0.029)\end{array}$ & & $\begin{array}{c}0.114^{* * *} \\
(0.029)\end{array}$ & & $\begin{array}{c}0.079^{* * *} \\
(0.023)\end{array}$ & & $\begin{array}{c}-0.024^{* * *} \\
(0.009)\end{array}$ \\
\hline $\log \left(\right.$ Employees $\left._{i s t}\right)$ & & -0.005 & & 0.007 & & $0.087^{* *}$ & & $0.070^{* * *}$ \\
\hline & & $(0.042)$ & & $(0.042)$ & & $(0.041)$ & & $(0.021)$ \\
\hline $\log \left(\right.$ Hours $\left._{i s t}\right)$ & & $0.540^{* * *}$ & & $0.365^{* * *}$ & & $0.458^{* * *}$ & & $0.061^{* * *}$ \\
\hline & & $(0.051)$ & & $(0.048)$ & & $(0.042)$ & & $(0.012)$ \\
\hline $\log \left(\right.$ Mines $\left._{s t}\right)$ & & -0.059 & & -0.077 & & -0.044 & & -0.028 \\
\hline & & $(0.065)$ & & $(0.080)$ & & $(0.071)$ & & $(0.019)$ \\
\hline Ultimate parent age $_{s t}$ & & 0.003 & & -0.010 & & 0.011 & & 0.011 \\
\hline & & $(0.009)$ & & $(0.017)$ & & $(0.009)$ & & $(0.016)$ \\
\hline Operator age ${ }_{i s t}$ & & -0.002 & & -0.003 & & 0.002 & & 0.001 \\
\hline & & $(0.003)$ & & $(0.003)$ & & $(0.004)$ & & $(0.001)$ \\
\hline Unionized $_{i s t}$ & & $\begin{array}{c}0.067 \\
(0.110)\end{array}$ & & $\begin{array}{l}0.168^{*} \\
(0.089)\end{array}$ & & $\begin{array}{c}0.058 \\
(0.118)\end{array}$ & & $\begin{array}{l}-0.046 \\
(0.050)\end{array}$ \\
\hline Year FE & Yes & Yes & Yes & Yes & Yes & Yes & Yes & Yes \\
\hline Mine FE & Yes & Yes & Yes & Yes & Yes & Yes & Yes & Yes \\
\hline County FE & Yes & Yes & Yes & Yes & Yes & Yes & Yes & Yes \\
\hline Inspection office FE & Yes & Yes & Yes & Yes & Yes & Yes & Yes & Yes \\
\hline Ultimate Parent FE & Yes & Yes & Yes & Yes & Yes & Yes & Yes & Yes \\
\hline Number of firms & 749 & 749 & 749 & 749 & 749 & 749 & 749 & 749 \\
\hline Observations & 12,173 & 12,173 & 12,173 & 12,173 & 12,173 & 12,173 & 12,173 & 12,173 \\
\hline$R^{2}$ & 0.772 & 0.843 & 0.798 & 0.838 & 0.732 & 0.802 & 0.417 & 0.428 \\
\hline
\end{tabular}




\section{Table 4: Listing Status and Mine-Level Fatalities}

This table reports the results of linear regression models in which the dependent variable is the the number of total fatalitiesat mine $i$, owned by ultimate parent $s$, during year $t$. Models (1) and (2) analyze all fatalities, while Models (3) and (4) include all the fatalities that stem from single-miner accidents. The sample consists of publicly- and privately-owned U.S. coal mines over a sample period of 1985 through 2018. The independent variable of interest is Public owner ${ }_{\text {ist }}$. All variable definitions appear in Appendix Table A.1. Data on mining fatalities, production, and employment, as well as ultimate mine ownership and mining acquisitions, are from the Mine Safety and Health Administration (MSHA) published through an Open Government Initiative. Data on listing status are hand-collected from firm filings, CRSP, CapitalIQ, and data on IPO dates from Jay Ritter's website. Robust standard errors, clustered at the ultimate parent level, are reported in parentheses. $*, * *$, and $* * *$ denote significance at the $10 \%, 5 \%$, and $1 \%$ level, respectively.

\begin{tabular}{|c|c|c|c|c|}
\hline \multirow[t]{2}{*}{ Dependent variable $=$} & \multicolumn{2}{|c|}{ Total fatalities ${ }_{i s t}$} & \multicolumn{2}{|c|}{$\begin{array}{c}\text { Total fatalities }{ }_{i s t} \\
\text { (single-miner accidents) }\end{array}$} \\
\hline & (1) & $(2)$ & $(3)$ & (4) \\
\hline Public owner $_{i s t}$ & $\begin{array}{c}0.097^{* *} \\
(0.040)\end{array}$ & $\begin{array}{c}0.097^{* *} \\
(0.041)\end{array}$ & $\begin{array}{c}0.062^{* * * *} \\
(0.022)\end{array}$ & $\begin{array}{c}0.059^{* * * *} \\
(0.020)\end{array}$ \\
\hline $\log \left(\right.$ Production $\left._{i s t}\right)$ & & $\begin{array}{c}0.002 \\
(0.003)\end{array}$ & & $\begin{array}{c}0.003 \\
(0.002)\end{array}$ \\
\hline $\log \left(\right.$ Employees $\left._{i s t}\right)$ & & $\begin{array}{c}0.012^{* * *} \\
(0.004)\end{array}$ & & $\begin{array}{c}0.013^{* * * *} \\
(0.004)\end{array}$ \\
\hline $\log \left(\right.$ Hours $\left._{i s t}\right)$ & & $\begin{array}{c}0.001 \\
(0.004)\end{array}$ & & $\begin{array}{l}-0.000 \\
(0.003)\end{array}$ \\
\hline $\log \left(\right.$ Mines $\left._{\text {ist }}\right)$ & & $\begin{array}{l}-0.006 \\
(0.009)\end{array}$ & & $\begin{array}{l}-0.006 \\
(0.008)\end{array}$ \\
\hline Ultimate parent age $_{s t}$ & & $\begin{array}{c}-0.001^{* * *} * \\
(0.000)\end{array}$ & & $\begin{array}{c}-0.001^{* * *} * \\
(0.000)\end{array}$ \\
\hline Operator age $_{i s t}$ & & $\begin{array}{c}0.001 \\
(0.001)\end{array}$ & & $\begin{array}{c}0.000 \\
(0.001)\end{array}$ \\
\hline Unionized $_{i s t}$ & & $\begin{array}{c}-0.026^{* *} \\
(0.013)\end{array}$ & & $\begin{array}{l}-0.012 \\
(0.009)\end{array}$ \\
\hline Year FE & Yes & Yes & Yes & Yes \\
\hline Mine FE & Yes & Yes & Yes & Yes \\
\hline County FE & Yes & Yes & Yes & Yes \\
\hline Ultimate Parent FE & Yes & Yes & Yes & Yes \\
\hline Number of firms & 1,411 & 1,411 & 1,411 & 1,411 \\
\hline Observations & 21,538 & 21,538 & 21,538 & 21,538 \\
\hline$R^{2}$ or Pseudo $R^{2}$ & 0.161 & 0.164 & 0.202 & 0.206 \\
\hline
\end{tabular}


Table 5: Listing Status and Mine-Level Labor Productivity

This table reports the results of linear regression models in which the dependent variable is the natural log of the total tons of clean coal produced divided by employee hours, or the natural log of the total tons of clean coal produced divided by the average number of employees at mine $i$, owned by ultimate parent $s$, during year $t$. The sample consists of publicly- and privately-owned U.S. coal mines over a sample period of 1985 through 2018. The independent variable of interest is Public owner ist. All variable definitions appear in Appendix Table A.1. Data on mining production and employment, as well as ultimate mine ownership and mining acquisitions, are from the Mine Safety and Health Administration (MSHA) published through an Open Government Initiative. Data on listing status are hand-collected from firm filings, CRSP, CapitalIQ, and data on IPO dates from Jay Ritter's website. Robust standard errors, clustered at the ultimate parent level, are reported in parentheses. *, **, and *** denote significance at the $10 \%, 5 \%$, and $1 \%$ level, respectively.

\begin{tabular}{|c|c|c|c|c|}
\hline \multirow[t]{2}{*}{ Dependent variable $=$} & \multicolumn{2}{|c|}{$\log \left(\right.$ Production/Hours $\left._{i s t}\right)$} & \multicolumn{2}{|c|}{$\log \left(\right.$ Production/Employees $\left._{i s t}\right)$} \\
\hline & $(1)$ & $(2)$ & $(3)$ & $(4)$ \\
\hline Public owner $_{i s t}$ & $\begin{array}{c}0.133 * * \\
(0.061)\end{array}$ & $\begin{array}{c}0.124^{* *} \\
(0.060)\end{array}$ & $\begin{array}{c}0.153^{* *} \\
(0.060)\end{array}$ & $\begin{array}{c}0.147^{* *} \\
(0.061)\end{array}$ \\
\hline $\log \left(\right.$ Mines $\left._{s t}\right)$ & & $\begin{array}{l}-0.036 \\
(0.035)\end{array}$ & & $\begin{array}{c}0.014 \\
(0.039)\end{array}$ \\
\hline Ultimate parent age $_{s t}$ & & $\begin{array}{c}0.017^{* * * *} \\
(0.005)\end{array}$ & & $\begin{array}{c}0.008 \\
(0.012)\end{array}$ \\
\hline Operator age $_{i s t}$ & & $\begin{array}{l}-0.003 \\
(0.002)\end{array}$ & & $\begin{array}{l}-0.002 \\
(0.003)\end{array}$ \\
\hline Unionized $_{i s t}$ & & $\begin{array}{c}0.096^{* * *} \\
(0.025)\end{array}$ & & $\begin{array}{l}0.076^{*} \\
(0.039)\end{array}$ \\
\hline Year FE & Yes & Yes & Yes & Yes \\
\hline Mine FE & Yes & Yes & Yes & Yes \\
\hline County FE & Yes & Yes & Yes & Yes \\
\hline Ultimate Parent FE & Yes & Yes & Yes & Yes \\
\hline Number of firms & 1,411 & 1,411 & 1,411 & 1,411 \\
\hline Observations & 21,538 & 21,538 & 21,538 & 21,538 \\
\hline$R^{2}$ & 0.703 & 0.703 & 0.603 & 0.603 \\
\hline
\end{tabular}


Table 6: Listing Status, Productivity Gains, and Mine-level Fatalities and Safety Violations

This table reports the results of linear regression models in which the dependent variable is either the total number of fatalities, or the natural log of one plus the number of safety violations at mine $i$, owned by ultimate parent $s$, during year $t$. The sample consists of publicly- and privately-owned U.S. coal mines over a sample period of 1985 through 2018 for fatalities, and 1993 through 2018 for safety violations. We split the sample into two subsamples based on the change in productivity (total tons of clean coal produced divided by employee hours per mine-year observation) over the life of the mine (the average productivity in the mine's last five producing years minus the average productivity in the mine's first five producing years). The independent variable of interest is Public owner. In Columns (3) through (8), the safety violations for constructing the dependent variables are split by the probability of an accident actually occurring, as deemed by the Mine Safety and Health Administration (MSHA) at the time of the citation for the safety violation. All variable definitions appear in Appendix Table A.1. Data on mining fatalities, safety violations, production, and employment, as well as ultimate mine ownership and mining acquisitions, are from the Mine Safety and Health Administration published through an Open Government Initiative. Data on listing status are hand-collected from firm filings, CRSP, CapitalIQ, and data on IPO dates from Jay Ritter's website. Robust standard errors, clustered at the ultimate level, are reported in parentheses. $*, * *$, and $* * *$ denote significance at the $10 \%, 5 \%$, and $1 \%$ level, respectively.

\begin{tabular}{|c|c|c|c|c|c|c|c|c|}
\hline \multirow{3}{*}{$\begin{array}{l}\text { Dependent variable }= \\
\text { MSHA Prob. of Accident }= \\
\text { Efficiency gain }=\end{array}$} & \multicolumn{8}{|c|}{$\log \left(1+\right.$ safety violations $\left._{i s t}\right)$} \\
\hline & \multicolumn{2}{|c|}{ All } & \multicolumn{2}{|c|}{ Low } & \multicolumn{2}{|c|}{ Medium } & \multicolumn{2}{|c|}{ High } \\
\hline & $\begin{array}{l}\mathrm{Big} \\
(1)\end{array}$ & $\begin{array}{c}\text { Small } \\
(2)\end{array}$ & $\begin{array}{c}\mathrm{Big} \\
(3)\end{array}$ & $\begin{array}{c}\text { Small } \\
(4)\end{array}$ & $\begin{array}{c}\mathrm{Big} \\
(5)\end{array}$ & $\begin{array}{c}\text { Small } \\
(6)\end{array}$ & $\begin{array}{l}\mathrm{Big} \\
(7)\end{array}$ & $\begin{array}{c}\text { Small } \\
(8)\end{array}$ \\
\hline Public owner $_{i s t}$ & $\begin{array}{c}0.525^{* *} \\
(0.219)\end{array}$ & $\begin{array}{c}-0.030 \\
(0.139)\end{array}$ & $\begin{array}{c}0.860^{* * * *} \\
(0.129)\end{array}$ & $\begin{array}{c}0.089 \\
(0.247)\end{array}$ & $\begin{array}{l}0.389^{*} \\
(0.212)\end{array}$ & $\begin{array}{c}-0.000 \\
(0.168)\end{array}$ & $\begin{array}{c}0.074 \\
(0.228)\end{array}$ & $\begin{array}{l}-0.102 \\
(0.110)\end{array}$ \\
\hline $\log \left(\right.$ Production $\left._{i s t}\right)$ & $\begin{array}{l}0.134^{*} \\
(0.072)\end{array}$ & $\begin{array}{c}0.123^{* * * *} \\
(0.028)\end{array}$ & $\begin{array}{l}0.117^{*} \\
(0.068)\end{array}$ & $\begin{array}{c}0.108^{* * *} \\
(0.027)\end{array}$ & $\begin{array}{c}0.136^{* *} \\
(0.062)\end{array}$ & $\begin{array}{c}0.062^{* *} \\
(0.025)\end{array}$ & $\begin{array}{l}-0.024 \\
(0.016)\end{array}$ & $\begin{array}{r}-0.022^{*} \\
(0.011)\end{array}$ \\
\hline $\log \left(\right.$ Employees $\left._{i s t}\right)$ & $\begin{array}{c}0.094 \\
(0.092)\end{array}$ & $\begin{array}{l}-0.021 \\
(0.051)\end{array}$ & $\begin{array}{c}0.079 \\
(0.115)\end{array}$ & $\begin{array}{l}-0.001 \\
(0.047)\end{array}$ & $\begin{array}{c}0.179^{* *} \\
(0.078)\end{array}$ & $\begin{array}{c}0.074 \\
(0.049)\end{array}$ & $\begin{array}{c}0.086^{* *} \\
(0.040)\end{array}$ & $\begin{array}{c}0.065^{* * *} * \\
(0.024)\end{array}$ \\
\hline $\log \left(\right.$ Hours $\left._{i s t}\right)$ & $\begin{array}{c}0.449^{* * * *} \\
(0.099)\end{array}$ & $\begin{array}{c}0.561^{* * * *} \\
(0.054)\end{array}$ & $\begin{array}{c}0.314^{* * * *} \\
(0.092)\end{array}$ & $\begin{array}{c}0.378^{* * * *} \\
(0.050)\end{array}$ & $\begin{array}{c}0.290^{* * * *} \\
(0.086)\end{array}$ & $\begin{array}{c}0.500^{* * * *} \\
(0.049)\end{array}$ & $\begin{array}{c}0.061^{* *} \\
(0.028)\end{array}$ & $\begin{array}{c}0.061 * * * \\
(0.014)\end{array}$ \\
\hline $\log \left(\right.$ Mines $\left._{s t}\right)$ & $\begin{array}{l}-0.109 \\
(0.131)\end{array}$ & $\begin{array}{l}-0.017 \\
(0.071)\end{array}$ & $\begin{array}{l}-0.126 \\
(0.145)\end{array}$ & $\begin{array}{l}-0.021 \\
(0.099)\end{array}$ & $\begin{array}{l}-0.111 \\
(0.104)\end{array}$ & $\begin{array}{c}0.001 \\
(0.087)\end{array}$ & $\begin{array}{l}-0.064 \\
(0.048)\end{array}$ & $\begin{array}{l}-0.025 \\
(0.033)\end{array}$ \\
\hline Ultimate parent age $_{s t}$ & & $\begin{array}{c}0.003 \\
(0.009)\end{array}$ & & $\begin{array}{l}-0.009 \\
(0.018)\end{array}$ & & $\begin{array}{c}0.011 \\
(0.010)\end{array}$ & & $\begin{array}{c}0.011 \\
(0.016)\end{array}$ \\
\hline${\text { Operator } \text { age }_{i s t}}$ & $\begin{array}{l}-0.002 \\
(0.004)\end{array}$ & $\begin{array}{l}-0.004 \\
(0.004)\end{array}$ & $\begin{array}{l}-0.003 \\
(0.003)\end{array}$ & $\begin{array}{l}-0.004 \\
(0.005)\end{array}$ & $\begin{array}{c}0.003 \\
(0.005)\end{array}$ & $\begin{array}{l}-0.002 \\
(0.004)\end{array}$ & $\begin{array}{c}0.003 \\
(0.002)\end{array}$ & $\begin{array}{l}-0.001 \\
(0.001)\end{array}$ \\
\hline Unionized $_{i s t}$ & $\begin{array}{l}-0.134 \\
(0.189)\end{array}$ & $\begin{array}{c}0.191 \\
(0.124)\end{array}$ & $\begin{array}{c}0.205 \\
(0.169)\end{array}$ & $\begin{array}{c}0.176 \\
(0.109)\end{array}$ & $\begin{array}{l}-0.170 \\
(0.184)\end{array}$ & $\begin{array}{c}0.198 \\
(0.142)\end{array}$ & $\begin{array}{l}-0.015 \\
(0.075)\end{array}$ & $\begin{array}{l}-0.060 \\
(0.067)\end{array}$ \\
\hline $\begin{array}{l}\text { F-stat (above-below) } \\
\text { (p-Value) }\end{array}$ & & $\begin{array}{l}6.29^{* *} \\
(0.012)\end{array}$ & & $\begin{array}{l}7.42^{* * *} \\
(0.007)\end{array}$ & & $\begin{array}{l}3.86^{* *} \\
(0.050)\end{array}$ & & $\begin{array}{c}1.00 \\
(0.318)\end{array}$ \\
\hline Year FE & Yes & Yes & Yes & Yes & Yes & Yes & Yes & Yes \\
\hline Mine FE & Yes & Yes & Yes & Yes & Yes & Yes & Yes & Yes \\
\hline County FE & Yes & Yes & Yes & Yes & Yes & Yes & Yes & Yes \\
\hline Inspection Office FE & Yes & Yes & Yes & Yes & Yes & Yes & Yes & Yes \\
\hline Ultimate Parent FE & Yes & Yes & Yes & Yes & Yes & Yes & Yes & Yes \\
\hline Number of firms & 231 & 670 & 231 & 670 & 231 & 670 & 231 & 670 \\
\hline Observations & 3,069 & 9,098 & 3,069 & 9,098 & 3,069 & 9,098 & 3,069 & 9,098 \\
\hline$R^{2}$ & 0.868 & 0.832 & 0.869 & 0.825 & 0.835 & 0.788 & 0.472 & 0.414 \\
\hline
\end{tabular}


Table 7: Listing Status, Coal Prices, and Workplace Safety and Productivity Tradeoffs

This table reports the results of linear regression models in which the dependent variable is either the total number of fatalities or the natural log of one plus the number of safety violations at mine $i$, owned by ultimate parent $s$, during year $t$ (Panel A), or the the natural log of the total tons of clean coal produced divided by employee hours or the natural log of the total tons of clean coal produced divided by the average number of employees at mine $i$, owned by ultimate parent $s$, during year $t$ (Panel B). The sample consists of publicly- and privately-owned U.S. coal mines over a sample period of 1993 through 2018 . We split the sample into two subsamples based on whether the average annual coal price for each state and mine type increases or decreases from the previous year. To avoid conflating tradeoff effects from large price increases, we drop observations in which the year-over-year price increase is larger than $30 \%$. This is equivalent to winsorizing (without replacement) at the $99 \%$ level. The independent variable of interest is Public owner ist. In Columns (3) through (8), the safety violations for constructing the dependent variables are split by the probability of an accident actually occurring, as deemed by the Mine Safety and Health Administration (MSHA) at the time of the citation for the safety violation. All variable definitions appear in Appendix Table A.1. Data on average annual coal sale prices is available from the U.S. Energy Information Administration (EIA) back to 1993. Data on mining fatalities, safety violations, production, and employment, as well as ultimate mine ownership and mining acquisitions, are from the Mine Safety and Health Administration published through an Open Government Initiative. Data on listing status are hand-collected from firm filings, CRSP, CapitalIQ, and data on IPO dates from Jay Ritter's website. Robust standard errors, clustered at the ultimate level, are reported in parentheses. *, **, and *** denote significance at the $10 \%, 5 \%$, and $1 \%$ level, respectively.

\begin{tabular}{|c|c|c|c|c|c|c|c|c|}
\hline \multicolumn{9}{|l|}{ Panel A } \\
\hline \multirow{3}{*}{$\begin{array}{l}\text { Dependent variable }= \\
\text { MSHA Prob. of Accident }= \\
\text { Coal price }(\text { YOY })=\end{array}$} & \multicolumn{8}{|c|}{$\log \left(1+\right.$ safety violations $\left.{ }_{i s t}\right)$} \\
\hline & \multicolumn{2}{|c|}{ All } & \multicolumn{2}{|c|}{ Low } & \multicolumn{2}{|c|}{ Medium } & \multicolumn{2}{|c|}{ High } \\
\hline & $\begin{array}{l}\text { Increase } \\
(1)\end{array}$ & $\begin{array}{c}\text { Decrease } \\
(2)\end{array}$ & $\begin{array}{c}\text { Increase } \\
(3)\end{array}$ & $\begin{array}{c}\text { Decrease } \\
(4)\end{array}$ & $\begin{array}{c}\text { Increase } \\
(5)\end{array}$ & $\begin{array}{c}\text { Decrease } \\
(6)\end{array}$ & $\begin{array}{c}\text { Increase } \\
(7)\end{array}$ & $\begin{array}{c}\text { Decrease } \\
(8)\end{array}$ \\
\hline Public owner $_{i s t}$ & $\begin{array}{l}-0.004 \\
(0.168)\end{array}$ & $\begin{array}{c}0.470 * * \\
(0.203)\end{array}$ & $\begin{array}{c}0.159 \\
(0.135)\end{array}$ & $\begin{array}{c}0.763^{* * *} \\
(0.135)\end{array}$ & $\begin{array}{c}0.025 \\
(0.178)\end{array}$ & $\begin{array}{c}0.333 \\
(0.236)\end{array}$ & $\begin{array}{c}0.000 \\
(0.126)\end{array}$ & $\begin{array}{c}-0.098 \\
(0.344)\end{array}$ \\
\hline $\log \left(\right.$ Production $\left._{i s t}\right)$ & $\begin{array}{c}0.140^{* * *} \\
(0.038)\end{array}$ & $\begin{array}{c}0.138^{* *} \\
(0.055)\end{array}$ & $\begin{array}{c}0.092^{* *} \\
(0.039)\end{array}$ & $\begin{array}{c}0.177^{* * *} * \\
(0.055)\end{array}$ & $\begin{array}{c}0.116^{* * *} \\
(0.030)\end{array}$ & $\begin{array}{c}0.036 \\
(0.050)\end{array}$ & $\begin{array}{c}-0.019 \\
(0.013)\end{array}$ & $\begin{array}{c}-0.036^{* *} \\
(0.017)\end{array}$ \\
\hline $\log \left(\right.$ Employees $\left._{i s t}\right)$ & $\begin{array}{l}-0.010 \\
(0.067)\end{array}$ & $\begin{array}{c}-0.008 \\
(0.087)\end{array}$ & $\begin{array}{l}-0.011 \\
(0.063)\end{array}$ & $\begin{array}{l}-0.027 \\
(0.071)\end{array}$ & $\begin{array}{c}0.121^{* *} \\
(0.060)\end{array}$ & $\begin{array}{c}0.024 \\
(0.084)\end{array}$ & $\begin{array}{c}0.083^{* * *} * \\
(0.025)\end{array}$ & $\begin{array}{c}0.078^{* * *} \\
(0.029)\end{array}$ \\
\hline $\log \left(\operatorname{Hours}_{i s t}\right)$ & $\begin{array}{c}0.539^{* * *} \\
(0.069)\end{array}$ & $\begin{array}{c}0.498^{* * *} \\
(0.094)\end{array}$ & $\begin{array}{c}0.429^{* * *} \\
(0.064)\end{array}$ & $\begin{array}{c}0.231^{* * *} \\
(0.080)\end{array}$ & $\begin{array}{c}0.413^{* * *} \\
(0.056)\end{array}$ & $\begin{array}{c}0.538^{* * *} \\
(0.088)\end{array}$ & $\begin{array}{c}0.052^{* * * *} \\
(0.018)\end{array}$ & $\begin{array}{c}0.061^{* *} \\
(0.025)\end{array}$ \\
\hline $\log \left(\right.$ Mines $\left._{s t}\right)$ & $\begin{array}{c}-0.032 \\
(0.102)\end{array}$ & $\begin{array}{c}-0.098 \\
(0.131)\end{array}$ & $\begin{array}{c}-0.054 \\
(0.121)\end{array}$ & $\begin{array}{c}-0.237^{*} \\
(0.131)\end{array}$ & $\begin{array}{l}-0.056 \\
(0.124)\end{array}$ & $\begin{array}{c}0.021 \\
(0.140)\end{array}$ & $\begin{array}{l}-0.068 \\
(0.043)\end{array}$ & $\begin{array}{c}-0.011 \\
(0.050)\end{array}$ \\
\hline Ultimate parent age $_{s t}$ & $\begin{array}{l}-0.007 \\
(0.006)\end{array}$ & $\begin{array}{c}0.857^{* * *} \\
(0.123)\end{array}$ & $\begin{array}{c}-0.009 \\
(0.015)\end{array}$ & $\begin{array}{c}1.089^{* * *} * \\
(0.134)\end{array}$ & $\begin{array}{c}-0.004 \\
(0.019)\end{array}$ & $\begin{array}{c}0.287^{* *} \\
(0.116)\end{array}$ & $\begin{array}{c}0.005 \\
(0.013)\end{array}$ & $\begin{array}{c}0.092^{*} \\
(0.051)\end{array}$ \\
\hline Operator age ${ }_{i s t}$ & $\begin{array}{l}-0.001 \\
(0.005)\end{array}$ & $\begin{array}{c}-0.005 \\
(0.006)\end{array}$ & $\begin{array}{l}-0.002 \\
(0.005)\end{array}$ & $\begin{array}{c}-0.006 \\
(0.007)\end{array}$ & $\begin{array}{c}0.004 \\
(0.007)\end{array}$ & $\begin{array}{l}-0.001 \\
(0.005)\end{array}$ & $\begin{array}{c}0.001 \\
(0.003)\end{array}$ & $\begin{array}{c}0.001 \\
(0.002)\end{array}$ \\
\hline Unionized $_{\text {ist }}$ & $\begin{array}{c}0.061 \\
(0.250)\end{array}$ & $\begin{array}{c}0.039 \\
(0.161)\end{array}$ & $\begin{array}{c}0.027 \\
(0.213)\end{array}$ & $\begin{array}{c}0.193 \\
(0.127)\end{array}$ & $\begin{array}{c}0.119 \\
(0.266)\end{array}$ & $\begin{array}{l}-0.020 \\
(0.169)\end{array}$ & $\begin{array}{l}-0.121 \\
(0.162)\end{array}$ & $\begin{array}{l}-0.082 \\
(0.086)\end{array}$ \\
\hline $\begin{array}{l}\text { F-stat (decrease-increase) } \\
\text { (p-Value) }\end{array}$ & & $\begin{array}{c}16.34^{* * *} \\
(0.000)\end{array}$ & & $\begin{array}{c}16.18^{* * *} \\
(0.000)\end{array}$ & & $\begin{array}{l}5.49^{* *} \\
(0.019)\end{array}$ & & $\begin{array}{c}0.19 \\
(0.666)\end{array}$ \\
\hline Year FE & Yes & Yes & Yes & Yes & Yes & Yes & Yes & Yes \\
\hline Mine FE & Yes & Yes & Yes & Yes & Yes & Yes & Yes & Yes \\
\hline County FE & Yes & Yes & Yes & Yes & Yes & Yes & Yes & Yes \\
\hline Inspection Office $\mathrm{FE}$ & Yes & Yes & Yes & Yes & Yes & Yes & Yes & Yes \\
\hline Ultimate Parent FE & Yes & Yes & Yes & Yes & Yes & Yes & Yes & Yes \\
\hline Number of firms & 503 & 457 & 503 & 457 & 503 & 457 & 503 & 457 \\
\hline Observations & 5,942 & 3,818 & 5,942 & 3,818 & 5,942 & 3,818 & 5,942 & 3,818 \\
\hline$R^{2}$ & 0.860 & 0.874 & 0.851 & 0.879 & 0.826 & 0.841 & 0.469 & 0.512 \\
\hline
\end{tabular}


Table 7 -continued

\begin{tabular}{|c|c|c|c|c|}
\hline \multicolumn{5}{|l|}{ Panel B } \\
\hline \multirow{2}{*}{$\begin{array}{l}\text { Dependent variable }= \\
\text { Coal price }(\mathrm{YOY})=\end{array}$} & \multicolumn{2}{|c|}{$\log \left(\right.$ Production/Hours $\left._{i s t}\right)$} & \multicolumn{2}{|c|}{$\log \left(\right.$ Production/Employees $\left._{i s t}\right)$} \\
\hline & $\begin{array}{l}\text { Increase } \\
(1)\end{array}$ & $\begin{array}{l}\text { Decrease } \\
\quad(2)\end{array}$ & $\begin{array}{c}\text { Increase } \\
(3)\end{array}$ & $\begin{array}{l}\text { Decrease } \\
(4)\end{array}$ \\
\hline Public owner $_{i s t}$ & $\begin{array}{l}-0.048 \\
(0.086)\end{array}$ & $\begin{array}{c}0.128^{* * *} \\
(0.040)\end{array}$ & $\begin{array}{l}-0.018 \\
(0.088)\end{array}$ & $\begin{array}{c}0.214^{* * *} \\
(0.054)\end{array}$ \\
\hline $\log \left(\right.$ Mines $\left._{s t}\right)$ & $\begin{array}{l}-0.016 \\
(0.081)\end{array}$ & $\begin{array}{l}-0.133^{*} \\
(0.075)\end{array}$ & $\begin{array}{c}0.010 \\
(0.085)\end{array}$ & $\begin{array}{l}-0.090 \\
(0.102)\end{array}$ \\
\hline Ultimate parent age $_{s t}$ & $\begin{array}{c}0.025^{* *} \\
(0.013)\end{array}$ & $\begin{array}{c}0.178^{* * * *} \\
(0.065)\end{array}$ & $\begin{array}{c}0.033 \\
(0.032)\end{array}$ & $\begin{array}{c}0.257^{* * *} \\
(0.078)\end{array}$ \\
\hline Operator age $\mathrm{e}_{i s t}$ & $\begin{array}{l}-0.001 \\
(0.005)\end{array}$ & $\begin{array}{c}-0.007^{* *} * \\
(0.003)\end{array}$ & $\begin{array}{c}0.001 \\
(0.006)\end{array}$ & $\begin{array}{l}-0.006 \\
(0.005)\end{array}$ \\
\hline Unionized $_{i s t}$ & $\begin{array}{c}0.377^{* * *} \\
(0.107)\end{array}$ & $\begin{array}{c}0.040 \\
(0.067)\end{array}$ & $\begin{array}{c}0.792^{* * *} \\
(0.219)\end{array}$ & $\begin{array}{c}0.126 \\
(0.116)\end{array}$ \\
\hline $\begin{array}{l}\text { F-stat (decrease - increase) } \\
\text { (p-Value) }\end{array}$ & & $\begin{array}{l}4.27^{* *} \\
(0.039)\end{array}$ & & $\begin{array}{l}5.32^{* *} \\
(0.021)\end{array}$ \\
\hline Year FE & Yes & Yes & Yes & Yes \\
\hline Mine FE & Yes & Yes & Yes & Yes \\
\hline County FE & Yes & Yes & Yes & Yes \\
\hline Ultimate Parent FE & Yes & Yes & Yes & Yes \\
\hline Number of firms & 503 & 457 & 503 & 457 \\
\hline Observations & 5,942 & 3,818 & 5,942 & 3,818 \\
\hline$R^{2}$ & 0.687 & 0.746 & 0.594 & 0.661 \\
\hline
\end{tabular}


Table 8: Proximity to Headquarters and Workplace Safety and Productivity Tradeoffs

This table reports the results of linear regression models in which the dependent variable is either the total number of fatalities or the natural log of one plus the number of safety violationsat mine $i$, owned by ultimate parent $s$, during year $t$ (Panel A), or the the natural log of the total tons of clean coal produced divided by employee hours or the natural log of the total tons of clean coal produced divided by the average number of employees at mine $i$, owned by ultimate parent $s$, during year tn (Panel B). The sample consists of publicly- and privately-owned US. coal mines over a sample period of 1993 through 2018 . We split the sample into two subsamples based on the distance (in miles) the mine is located from the ultimate parent headquarters. We define a mine to be far from its headquarters if it is in the upper tertile of distances in our sample (greater than or equal to 105 miles), and near if it is in the lower two tertiles of distances in our sample (lower than 105 miles). The independent variable of interest is Public owner ist. In Columns (3) through (8), the safety violations for constructing the dependent variables are split by the probability of an accident actually occurring, as deemed by the Mine Safety and Health Administration (MSHA) at the time of the citation for the safety violation. All variable definitions appear in Appendix Table A.1. Data on mining fatalities, safety violations, production, and employment, as well as ultimate mine ownership and mining acquisitions, are from the Mine Safety and Health Administration published through an Open Government Initiative. Data on listing status are hand-collected from firm filings, CRSP, CapitalIQ, and data on IPO dates from Jay Ritter's website. Robust standard errors, clustered at the ultimate level, are reported in parentheses. *, **, and *** denote significance at the $10 \%, 5 \%$, and $1 \%$ level, respectively.

\begin{tabular}{|c|c|c|c|c|c|c|c|c|}
\hline \multicolumn{9}{|l|}{ Panel $A$} \\
\hline \multirow{3}{*}{$\begin{array}{l}\text { Dependent variable }= \\
\text { MSHA Prob. of Accident }= \\
\text { Distance from } \mathrm{HQ}=\end{array}$} & \multicolumn{8}{|c|}{$\log \left(1+\right.$ safety violations $\left._{i s t}\right)$} \\
\hline & \multicolumn{2}{|c|}{ All } & \multicolumn{2}{|c|}{ Low } & \multicolumn{2}{|c|}{ Medium } & \multicolumn{2}{|c|}{ High } \\
\hline & $\begin{array}{c}\text { Far } \\
(1)\end{array}$ & $\begin{array}{l}\text { Near } \\
(2)\end{array}$ & $\begin{array}{c}\text { Far } \\
(3)\end{array}$ & $\begin{array}{l}\text { Near } \\
(4)\end{array}$ & $\begin{array}{c}\text { Far } \\
(5)\end{array}$ & $\begin{array}{c}\text { Near } \\
(6)\end{array}$ & $\begin{array}{l}\text { Far } \\
(7)\end{array}$ & $\begin{array}{c}\text { Near } \\
(8)\end{array}$ \\
\hline Public owner $_{i s t}$ & $\begin{array}{c}0.061 \\
(0.280)\end{array}$ & $\begin{array}{c}0.425^{* * *} \\
(0.117)\end{array}$ & $\begin{array}{l}0.260^{*} \\
(0.153)\end{array}$ & $\begin{array}{c}0.831^{* * * *} \\
(0.141)\end{array}$ & $\begin{array}{c}0.059 \\
(0.317)\end{array}$ & $\begin{array}{c}0.262^{* * *} \\
(0.098)\end{array}$ & $\begin{array}{l}-0.083 \\
(0.217)\end{array}$ & $\begin{array}{l}0.133^{*} \\
(0.074)\end{array}$ \\
\hline $\log \left(\right.$ Production $\left._{i s t}\right)$ & $\begin{array}{c}0.117^{* * *} \\
(0.042)\end{array}$ & $\begin{array}{c}0.133^{* * *} \\
(0.048)\end{array}$ & $\begin{array}{c}0.076 \\
(0.049)\end{array}$ & $\begin{array}{l}0.083^{*} \\
(0.048)\end{array}$ & $\begin{array}{l}0.075^{*} \\
(0.040)\end{array}$ & $\begin{array}{c}0.112^{* * *} \\
(0.035)\end{array}$ & $\begin{array}{c}-0.056^{* * *} \\
(0.020)\end{array}$ & $\begin{array}{l}0.001 \\
(0.010)\end{array}$ \\
\hline $\log \left(\right.$ Employees $\left._{i s t}\right)$ & $\begin{array}{c}0.077 \\
(0.070)\end{array}$ & $\begin{array}{l}-0.063 \\
(0.064)\end{array}$ & $\begin{array}{r}0.147^{* *} \\
(0.074)\end{array}$ & $\begin{array}{l}-0.094 \\
(0.064)\end{array}$ & $\begin{array}{c}0.116 \\
(0.099)\end{array}$ & $\begin{array}{l}0.021 \\
(0.058)\end{array}$ & $\begin{array}{l}0.055 \\
(0.036)\end{array}$ & $\begin{array}{c}0.057^{* * *} \\
(0.021)\end{array}$ \\
\hline $\log \left(\right.$ Hours $\left._{i s t}\right)$ & $\begin{array}{c}0.584^{* * * *} \\
(0.071)\end{array}$ & $\begin{array}{c}0.498^{* * *} \\
(0.070)\end{array}$ & $\begin{array}{c}0.458^{* * *} \\
(0.073)\end{array}$ & $\begin{array}{c}0.363^{* * *} * \\
(0.068)\end{array}$ & $\begin{array}{c}0.514^{* * *} \\
(0.064)\end{array}$ & $\begin{array}{c}0.389^{* * *} \\
(0.057)\end{array}$ & $\begin{array}{c}0.108^{* * *} \\
(0.027)\end{array}$ & $\begin{array}{c}0.030^{* *} \\
(0.014)\end{array}$ \\
\hline $\log \left(\right.$ Mines $\left._{s t}\right)$ & -0.106 & -0.002 & -0.059 & -0.067 & -0.134 & 0.031 & $-0.054^{* *}$ & -0.007 \\
\hline Ultimate parent age ${ }_{s t}$ & $\begin{array}{c}(0.116) \\
-0.009 \\
(0.006)\end{array}$ & $(0.069)$ & $\begin{array}{c}(0.113) \\
-0.025 \\
(0.016)\end{array}$ & $(0.105)$ & $\begin{array}{c}(0.137) \\
0.007 \\
(0.015)\end{array}$ & $(0.058)$ & $\begin{array}{c}(0.023) \\
0.009 \\
(0.016)\end{array}$ & $(0.034)$ \\
\hline Operator age $_{i s t}$ & $\begin{array}{l}-0.003 \\
(0.006)\end{array}$ & $\begin{array}{l}-0.004 \\
(0.003)\end{array}$ & $\begin{array}{l}-0.001 \\
(0.005)\end{array}$ & $\begin{array}{l}-0.005 \\
(0.003)\end{array}$ & $\begin{array}{c}0.000 \\
(0.006)\end{array}$ & $\begin{array}{l}0.000 \\
(0.004)\end{array}$ & $\begin{array}{c}0.001 \\
(0.004)\end{array}$ & $\begin{array}{l}0.002^{*} \\
(0.001)\end{array}$ \\
\hline Unionized $_{i s t}$ & $\begin{array}{l}0.077 \\
(0.169)\end{array}$ & $\begin{array}{c}0.122 \\
(0.199)\end{array}$ & $\begin{array}{l}-0.066 \\
(0.179)\end{array}$ & $\begin{array}{l}0.255^{*} \\
(0.141)\end{array}$ & $\begin{array}{c}0.184 \\
(0.214)\end{array}$ & $\begin{array}{l}0.068 \\
(0.213)\end{array}$ & $\begin{array}{l}-0.047 \\
(0.085)\end{array}$ & $\begin{array}{l}-0.074 \\
(0.080)\end{array}$ \\
\hline $\begin{array}{l}\text { F-stat (near-far) } \\
\text { (p-Value) }\end{array}$ & & $\begin{array}{c}1.28 \\
(0.258)\end{array}$ & & $\begin{array}{l}7.02^{* * *} \\
(0.008)\end{array}$ & & $\begin{array}{c}0.35 \\
(0.553)\end{array}$ & & $\begin{array}{c}1.12 \\
(0.290)\end{array}$ \\
\hline Year FE & Yes & Yes & Yes & Yes & Yes & Yes & Yes & Yes \\
\hline & Yes & Yes & Yes & Yes & Yes & Yes & Yes & Yes \\
\hline County FE & Yes & Yes & Yes & Yes & Yes & Yes & Yes & Yes \\
\hline ion Office FE & Yes & Yes & Yes & Yes & Yes & Yes & Yes & Yes \\
\hline Ultimate Parent FE & Yes & Yes & Yes & Yes & Yes & Yes & Yes & Yes \\
\hline Number of firms & 148 & 436 & 148 & 436 & 148 & 436 & 148 & 436 \\
\hline Observations & 3,164 & 6,332 & 3,164 & 6,332 & 3,164 & 6,332 & 3,164 & 6,332 \\
\hline$R^{2}$ & 0.873 & 0.828 & 0.872 & 0.818 & 0.825 & 0.796 & 0.462 & 0.438 \\
\hline
\end{tabular}


Table 8 -continued

\begin{tabular}{|c|c|c|c|c|}
\hline \multicolumn{5}{|l|}{ Panel B } \\
\hline \multirow{2}{*}{$\begin{array}{l}\text { Dependent variable }= \\
\text { Distance from } \mathrm{HQ}=\end{array}$} & \multicolumn{2}{|c|}{$\log \left(\right.$ Production/Hours $\left._{i s t}\right)$} & \multicolumn{2}{|c|}{$\log \left(\right.$ Production/Employees $\left._{i s t}\right)$} \\
\hline & $\begin{array}{l}\text { Far } \\
(1)\end{array}$ & $\begin{array}{c}\text { Near } \\
(2)\end{array}$ & $\begin{array}{l}\text { Far } \\
(3)\end{array}$ & $\begin{array}{c}\text { Near } \\
(4)\end{array}$ \\
\hline Public owner $_{i s t}$ & $\begin{array}{l}-0.013 \\
(0.085)\end{array}$ & $\begin{array}{c}0.175^{* * *} \\
(0.055)\end{array}$ & $\begin{array}{l}-0.058 \\
(0.072)\end{array}$ & $\begin{array}{c}0.235^{* *} \\
(0.094)\end{array}$ \\
\hline $\log \left(\right.$ Mines $\left._{s t}\right)$ & $\begin{array}{l}-0.016 \\
(0.063)\end{array}$ & $\begin{array}{r}-0.067^{*} \\
(0.037)\end{array}$ & $\begin{array}{c}0.027 \\
(0.067)\end{array}$ & $\begin{array}{l}-0.021 \\
(0.047)\end{array}$ \\
\hline Ultimate parent age $_{s t}$ & $\begin{array}{l}0.012^{*} \\
(0.007)\end{array}$ & & $\begin{array}{l}0.005 \\
(0.013)\end{array}$ & \\
\hline Operator age $e_{i s t}$ & $\begin{array}{l}-0.005 \\
(0.008)\end{array}$ & $\begin{array}{l}-0.002 \\
(0.003)\end{array}$ & $\begin{array}{l}-0.008 \\
(0.011)\end{array}$ & $\begin{array}{l}-0.001 \\
(0.004)\end{array}$ \\
\hline Unionized $_{i s t}$ & $\begin{array}{c}0.118^{* *} \\
(0.058)\end{array}$ & $\begin{array}{c}0.109^{* * *} \\
(0.039)\end{array}$ & $\begin{array}{c}0.154^{* *} \\
(0.073)\end{array}$ & $\begin{array}{c}0.134^{* *} \\
(0.058)\end{array}$ \\
\hline $\begin{array}{l}\text { F-stat (near-far) } \\
\text { (p-Value) }\end{array}$ & & $\begin{array}{l}2.95^{*} \\
(0.086)\end{array}$ & & $\begin{array}{l}4.93^{* *} \\
(0.027)\end{array}$ \\
\hline Year FE & Yes & Yes & Yes & Yes \\
\hline Mine FE & Yes & Yes & Yes & Yes \\
\hline County FE & Yes & Yes & Yes & Yes \\
\hline Ultimate Parent FE & Yes & Yes & Yes & Yes \\
\hline Number of firms & 208 & 566 & 208 & 566 \\
\hline Observations & 4,875 & 10,072 & 4,875 & 10,072 \\
\hline$R^{2}$ & 0.766 & 0.652 & 0.649 & 0.549 \\
\hline
\end{tabular}




\section{Table 10: MSHA Inspection Office Changes and Workplace Safety and Productivity Tradeoffs}

This table reports the results of linear regression models surrounding changes in the inspection office assigned for overseeing mine safety. The dependent variable is either the natural log of one plus the number of safety violations," or the the natural log of the total tons of clean coal produced divided by employee hours (Model (5)) or the average number of employees (Model (6)) at mine $i$, owned by ultimate parent $s$, during year $t$. The sample consists of publicly- and privately-owned U.S. coal mines over a sample period of 1993 through 2018 for safety violations, and 1985 through 2018 for productivity. Post is equal to 1 if a mine's inspection office has changed as of time t, and 0 otherwise. Change is equal to -1 for an inspection office change to an office at least 60 miles closer to the mine, 1 for an inspection office change to an

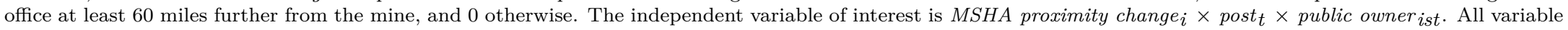
definitions appear in Appendix Table A.1. Data on mining fatalities, safety violations, production, and employment, as well as ultimate mine ownership and mining acquisitions, are from the Mine Safety and Health Administration published through an Open Government Initiative. Data on listing status are hand-collected from firm filings, CRSP, CapitalIQ, and data on IPO dates from Jay Ritter's website. Robust standard errors, clustered at the ultimate level, are reported in parentheses. *, **, and $* * *$ denote significance at the $10 \%, 5 \%$, and $1 \%$ level, respectively.

\begin{tabular}{|c|c|c|c|c|c|c|}
\hline \multirow{3}{*}{$\begin{array}{l}\text { Dependent variable }= \\
\text { MSHA Prob. of Accident }=\end{array}$} & \multicolumn{4}{|c|}{$\log \left(1+\right.$ Safety violations $\left.{ }_{i s t}\right)$} & \multirow{2}{*}{\multicolumn{2}{|c|}{$\frac{\log \left(\text { Productivity }_{i s t}\right)}{\text { N/A }}$}} \\
\hline & \multirow{2}{*}{$\begin{array}{l}\text { All } \\
(1) \\
\end{array}$} & \multirow{2}{*}{$\begin{array}{c}\text { Low } \\
(2) \\
\end{array}$} & \multirow{2}{*}{$\begin{array}{c}\text { Med. } \\
(3) \\
\end{array}$} & \multirow{2}{*}{$\begin{array}{c}\text { High } \\
(4) \\
\end{array}$} & & \\
\hline & & & & & $(5)$ & $(6)$ \\
\hline MSHA proximity change $i \times$ post $_{t} \times$ public owner $_{i s t}$ & $\begin{array}{c}0.287 \\
(0.224)\end{array}$ & $\begin{array}{c}0.431^{* *} \\
(0.203)\end{array}$ & $\begin{array}{l}0.429^{*} \\
(0.231)\end{array}$ & $\begin{array}{l}-0.070 \\
(0.144)\end{array}$ & $\begin{array}{l}0.147^{*} \\
(0.077)\end{array}$ & $\begin{array}{c}0.283^{* *} \\
(0.133)\end{array}$ \\
\hline Public owner $_{i s t}$ & $\begin{array}{c}0.224 \\
(0.172)\end{array}$ & $\begin{array}{c}0.465^{* * *} \\
(0.158)\end{array}$ & $\begin{array}{c}0.165 \\
(0.179)\end{array}$ & $\begin{array}{l}-0.009 \\
(0.171)\end{array}$ & $\begin{array}{r}0.075^{* *} \\
(0.033)\end{array}$ & $\begin{array}{c}0.126^{* *} \\
(0.051)\end{array}$ \\
\hline $\log \left(\right.$ Production $\left._{\text {ist }}\right)$ & $\begin{array}{c}0.120^{* * *} \\
(0.029)\end{array}$ & $\begin{array}{c}0.106^{* * *} \\
(0.029)\end{array}$ & $\begin{array}{c}0.078^{* * *} \\
(0.023)\end{array}$ & $\begin{array}{c}-0.025^{* * *} \\
(0.009)\end{array}$ & & \\
\hline $\log \left(\right.$ Employees $\left._{i s t}\right)$ & $\begin{array}{l}0.003 \\
(0.042)\end{array}$ & $\begin{array}{l}0.015 \\
(0.043)\end{array}$ & $\begin{array}{c}0.090^{* *} \\
(0.041)\end{array}$ & $\begin{array}{c}0.073^{* * *} \\
(0.021)\end{array}$ & & \\
\hline $\log \left(\right.$ Hours $\left._{i s t}\right)$ & $\begin{array}{c}0.548^{* * *} \\
(0.050)\end{array}$ & $\begin{array}{c}0.373^{* * *} \\
(0.048)\end{array}$ & $\begin{array}{c}0.460^{* * *} \\
(0.043)\end{array}$ & $\begin{array}{c}0.061^{* * *} \\
(0.012)\end{array}$ & & \\
\hline $\log \left(\right.$ Mines $\left._{s t}\right)$ & $\begin{array}{l}-0.062 \\
(0.065)\end{array}$ & $\begin{array}{l}-0.086 \\
(0.080)\end{array}$ & $\begin{array}{l}-0.042 \\
(0.071)\end{array}$ & $\begin{array}{l}-0.030 \\
(0.019)\end{array}$ & $\begin{array}{l}-0.033 \\
(0.022)\end{array}$ & $\begin{array}{c}0.003 \\
(0.038)\end{array}$ \\
\hline Ultimate parent age $_{s t}$ & $\begin{array}{l}-0.002 \\
(0.007)\end{array}$ & $\begin{array}{l}-0.016 \\
(0.017)\end{array}$ & $\begin{array}{l}0.006 \\
(0.011)\end{array}$ & $\begin{array}{l}0.010 \\
(0.016)\end{array}$ & $\begin{array}{c}0.012^{* * *} * \\
(0.004)\end{array}$ & $\begin{array}{c}0.009 \\
(0.013)\end{array}$ \\
\hline Operator age $_{i s t}$ & $\begin{array}{l}-0.002 \\
(0.003)\end{array}$ & $\begin{array}{l}-0.003 \\
(0.003)\end{array}$ & $\begin{array}{c}0.002 \\
(0.004)\end{array}$ & $\begin{array}{l}0.001 \\
(0.001)\end{array}$ & $\begin{array}{l}-0.002 \\
(0.001)\end{array}$ & $\begin{array}{l}-0.002 \\
(0.003)\end{array}$ \\
\hline Unionized $_{i s t}$ & $\begin{array}{c}0.046 \\
(0.115)\end{array}$ & $\begin{array}{l}0.150^{*} \\
(0.090)\end{array}$ & $\begin{array}{c}0.049 \\
(0.125)\end{array}$ & $\begin{array}{l}-0.057 \\
(0.049)\end{array}$ & $\begin{array}{c}0.058^{* * *} \\
(0.015)\end{array}$ & $\begin{array}{l}0.072^{*} \\
(0.039)\end{array}$ \\
\hline MSHA proximity change $_{i} \times$ post $_{t}$ & $\begin{array}{l}-0.252 \\
(0.182)\end{array}$ & $\begin{array}{l}-0.242 \\
(0.252)\end{array}$ & $\begin{array}{c}-0.271^{*} \\
(0.164)\end{array}$ & $\begin{array}{l}-0.140 \\
(0.126)\end{array}$ & $\begin{array}{l}-0.083 \\
(0.089)\end{array}$ & $\begin{array}{l}-0.236 \\
(0.206)\end{array}$ \\
\hline MSHA proximity change $_{i} \times$ public owner $_{i s t}$ & $\begin{array}{l}-0.103 \\
(0.348)\end{array}$ & $\begin{array}{c}0.191 \\
(0.295)\end{array}$ & $\begin{array}{l}-0.046 \\
(0.298)\end{array}$ & $\begin{array}{l}0.286^{* *} \\
(0.139)\end{array}$ & $\begin{array}{l}-0.020 \\
(0.079)\end{array}$ & $\begin{array}{l}0.045 \\
(0.102)\end{array}$ \\
\hline Post $_{t} \times$ public owner $_{i s t}$ & $\begin{array}{l}-0.131 \\
(0.294)\end{array}$ & $\begin{array}{l}-0.364 \\
(0.259)\end{array}$ & $\begin{array}{c}0.046 \\
(0.330)\end{array}$ & $\begin{array}{l}0.424^{* *} \\
(0.175)\end{array}$ & $\begin{array}{l}-0.016 \\
(0.099)\end{array}$ & $\begin{array}{l}0.026 \\
(0.151)\end{array}$ \\
\hline Post $_{t}$ & $\begin{array}{c}0.175 \\
(0.128)\end{array}$ & $\begin{array}{c}0.023 \\
(0.150)\end{array}$ & $\begin{array}{c}0.151 \\
(0.174)\end{array}$ & $\begin{array}{c}0.102 \\
(0.134)\end{array}$ & $\begin{array}{l}-0.048 \\
(0.090)\end{array}$ & $\begin{array}{c}0.046 \\
(0.153)\end{array}$ \\
\hline Year FE & Yes & Yes & Yes & Yes & Yes & Yes \\
\hline & Yes & Yes & Yes & $\mathrm{Ye}$ & $\mathrm{Ye}$ & Yes \\
\hline County FE & Yes & Yes & Yes & Yes & Yes & Yes \\
\hline Inspection office $\mathrm{FE}$ & Yes & Yes & Yes & Yes & Yes & Yes \\
\hline Ultimate Parent FE & Yes & Yes & Yes & Yes & Yes & Yes \\
\hline Number of firms & 747 & 747 & 747 & 747 & 1,410 & 1,410 \\
\hline Observations & 12,012 & 12,012 & 12,012 & 12,012 & 21,377 & 21,377 \\
\hline$R^{2}$ & 0.845 & 0.840 & 0.803 & 0.429 & 0.774 & 0.605 \\
\hline
\end{tabular}


Table 11: Placebo Results

This table reports the results of linear regression models in which the dependent variable is the natural log of one plus the number of safety violations, the total number of fatalities, or the natural log of total tons of clean coal produced divided by employee hours (Model (6)) or average employees (Model (7)) at mine $i$, owned by ultimate parent $s$, during year $t$. The sample consists of publicly- and privately-owned U.S. coal mines over a sample period of 1985 through 2018 for productivity and fatalities, and 1993 through 2018 for safety violations. The dependent variable of interest is Placebo ist. Placeboist is an indicator equal to one if the observation is in the two-year period $(t=-1$ or $t=-2)$ prior to a change in listing status for mine $i$. All variable definitions appear in Appendix Table A.1. Data on mining fatalities, safety violations, production, and employment, as well as ultimate mine ownership and mining acquisitions, are from the Mine Safety and Health Administration published through an Open Government Initiative. Data on listing status are hand-collected from firm filings, CRSP, CapitalIQ, and data on IPO dates from Jay Ritter's website. Robust standard errors, clustered at the ultimate parent level, are reported in parentheses. *, $* *$, and $* * *$ denote significance at the $10 \%, 5 \%$, and $1 \%$ level, respectively.

\begin{tabular}{|c|c|c|c|c|c|c|c|}
\hline \multirow{3}{*}{$\begin{array}{l}\text { Dependent variable }= \\
\text { MSHA Prob. of Accident }=\end{array}$} & \multicolumn{4}{|c|}{$\log \left(1+\right.$ safety violations $\left._{i s t}\right)$} & Total fatalities $i s t$ & \multirow{2}{*}{\multicolumn{2}{|c|}{$\frac{\log \left(\text { Productivity }_{i s t}\right)}{\mathrm{N} / \mathrm{A}}$}} \\
\hline & All & Low & Medium & High & & & \\
\hline & (1) & $(2)$ & $(3)$ & $(4)$ & $(5)$ & (6) & $(7)$ \\
\hline Placebo $_{i s t}$ & $\begin{array}{l}-0.008 \\
(0.085)\end{array}$ & $\begin{array}{l}-0.024 \\
(0.075)\end{array}$ & $\begin{array}{l}-0.036 \\
(0.083)\end{array}$ & $\begin{array}{l}-0.002 \\
(0.050)\end{array}$ & $\begin{array}{l}-0.004 \\
(0.016)\end{array}$ & $\begin{array}{c}0.034 \\
(0.075)\end{array}$ & $\begin{array}{c}0.076 \\
(0.088)\end{array}$ \\
\hline Public owner $_{i s t}$ & $\begin{array}{c}0.233 \\
(0.176)\end{array}$ & $\begin{array}{c}0.443^{* *} \\
(0.179)\end{array}$ & $\begin{array}{c}0.173 \\
(0.176)\end{array}$ & $\begin{array}{l}-0.019 \\
(0.160)\end{array}$ & $\begin{array}{c}0.096^{* *} \\
(0.042)\end{array}$ & $\begin{array}{l}0.131^{*} \\
(0.069)\end{array}$ & $\begin{array}{c}0.162^{* *} \\
(0.065)\end{array}$ \\
\hline $\log \left(\right.$ Production $\left._{i s t}\right)$ & $\begin{array}{c}0.127 * * * \\
(0.029)\end{array}$ & $\begin{array}{c}0.114^{* * * *} \\
(0.029)\end{array}$ & $\begin{array}{c}0.079^{* * * *} \\
(0.023)\end{array}$ & $\begin{array}{c}-0.024^{* * * *} \\
(0.009)\end{array}$ & $\begin{array}{c}0.002 \\
(0.003)\end{array}$ & & \\
\hline $\log \left(\right.$ Employees $\left._{i s t}\right)$ & $\begin{array}{l}-0.005 \\
(0.042)\end{array}$ & $\begin{array}{c}0.007 \\
(0.042)\end{array}$ & $\begin{array}{c}0.087^{* *} \\
(0.041)\end{array}$ & $\begin{array}{c}0.070^{* * *} \\
(0.021)\end{array}$ & $\begin{array}{c}0.012^{* * * *} \\
(0.004)\end{array}$ & & \\
\hline $\log \left(\right.$ Hours $\left._{i s t}\right)$ & $\begin{array}{c}0.540^{* * *} \\
(0.049)\end{array}$ & $\begin{array}{c}0.364^{* * * *} \\
(0.048)\end{array}$ & $\begin{array}{c}0.457^{* * * *} \\
(0.041)\end{array}$ & $\begin{array}{c}0.061^{* * *} \\
(0.012)\end{array}$ & $\begin{array}{c}0.001 \\
(0.004)\end{array}$ & & \\
\hline $\log \left(\right.$ Mines $\left._{s t}\right)$ & $\begin{array}{l}-0.060 \\
(0.065)\end{array}$ & $\begin{array}{l}-0.079 \\
(0.079)\end{array}$ & $\begin{array}{l}-0.046 \\
(0.072)\end{array}$ & $\begin{array}{l}-0.028 \\
(0.019)\end{array}$ & $\begin{array}{l}-0.006 \\
(0.009)\end{array}$ & $\begin{array}{l}-0.035 \\
(0.035)\end{array}$ & $\begin{array}{c}0.015 \\
(0.039)\end{array}$ \\
\hline Ultimate parent age $_{s t}$ & $\begin{array}{c}0.003 \\
(0.009)\end{array}$ & $\begin{array}{l}-0.010 \\
(0.017)\end{array}$ & $\begin{array}{c}0.011 \\
(0.009)\end{array}$ & $\begin{array}{c}0.011 \\
(0.016)\end{array}$ & $\begin{array}{c}-0.001^{* * * *} \\
(0.000)\end{array}$ & $\begin{array}{c}0.017^{* * * *} \\
(0.005)\end{array}$ & $\begin{array}{c}0.009 \\
(0.011)\end{array}$ \\
\hline Operator age ${ }_{i s t}$ & $\begin{array}{l}-0.002 \\
(0.003)\end{array}$ & $\begin{array}{l}-0.003 \\
(0.003)\end{array}$ & $\begin{array}{c}0.002 \\
(0.004)\end{array}$ & $\begin{array}{c}0.001 \\
(0.001)\end{array}$ & $\begin{array}{c}0.001 \\
(0.001)\end{array}$ & $\begin{array}{l}-0.003 \\
(0.002)\end{array}$ & $\begin{array}{l}-0.002 \\
(0.003)\end{array}$ \\
\hline Unionized $_{i s t}$ & $\begin{array}{c}0.067 \\
(0.110)\end{array}$ & $\begin{array}{l}0.167^{*} \\
(0.090)\end{array}$ & $\begin{array}{l}0.055 \\
(0.117)\end{array}$ & $\begin{array}{l}-0.046 \\
(0.051)\end{array}$ & $\begin{array}{c}-0.026^{* *} \\
(0.013)\end{array}$ & $\begin{array}{c}0.096^{* * *} \\
(0.025)\end{array}$ & $\begin{array}{l}0.076^{*} \\
(0.039)\end{array}$ \\
\hline Year FE & Yes & Yes & $\mathrm{Ye}$ & Yes & $\mathrm{Ye}$ & Ye & Yes \\
\hline Mine FE & Yes & Yes & Yes & Yes & Yes & Yes & Yes \\
\hline County FE & Yes & Yes & Yes & Yes & Yes & Yes & Yes \\
\hline Inspection Office FE & Yes & Yes & Yes & Yes & No & No & No \\
\hline Ultimate Parent FE & Yes & Yes & Yes & Yes & Yes & Yes & Yes \\
\hline Number of firms & 749 & 749 & 749 & 749 & 1,411 & 1,411 & 1,411 \\
\hline Observations & 12,173 & 12,173 & 12,173 & 12,173 & 21,538 & 21,538 & 21,538 \\
\hline$R^{2}$ & 0.843 & 0.838 & 0.802 & 0.428 & 0.164 & 0.703 & 0.603 \\
\hline
\end{tabular}


Table 12: MSHA Inspection Office Change Predictors

This table reports the results of linear regression models in which the dependent variable is an indicator variable equal to one if mine $i$ experiences a MSHA inspection office move or reassignment from MSHA inspection office $j$ to another location at time $t+1$. All dependent variables are measured at time $t$. Robust standard errors, clustered at the ultimate parent level, are reported in parentheses. $*, * *$, and $* * *$ denote significance at the $10 \%, 5 \%$, and $1 \%$ level, respectively.

\begin{tabular}{|c|c|c|c|c|c|c|}
\hline \multirow{3}{*}{$\begin{array}{l}\text { Dependent variable }= \\
\text { Proximity change }=\end{array}$} & \multicolumn{6}{|c|}{ Indicator(MSHA inspection office change) ${ }_{t+1}$} \\
\hline & \multicolumn{4}{|c|}{ Both } & \multirow{2}{*}{$\frac{\text { Decrease }}{(5)}$} & \multirow{2}{*}{$\frac{\text { Increase }}{(6)}$} \\
\hline & $(1)$ & $(2)$ & $(3)$ & $(4)$ & & \\
\hline Public owner $_{i s t}$ & $\begin{array}{l}-0.008 \\
(0.006)\end{array}$ & $\begin{array}{l}-0.008 \\
(0.006)\end{array}$ & $\begin{array}{c}0.002 \\
(0.005)\end{array}$ & $\begin{array}{l}-0.011 \\
(0.007)\end{array}$ & $\begin{array}{l}-0.007 \\
(0.006)\end{array}$ & $\begin{array}{l}-0.003 \\
(0.009)\end{array}$ \\
\hline $\log \left(\right.$ Mines in inspection district $\left._{j t}\right)$ & $\begin{array}{c}-0.012^{* * *} \\
(0.003)\end{array}$ & $\begin{array}{c}-0.009^{* * *} \\
(0.003)\end{array}$ & $\begin{array}{c}0.001 \\
(0.006)\end{array}$ & $\begin{array}{c}0.002 \\
(0.007)\end{array}$ & $\begin{array}{c}0.006 \\
(0.005)\end{array}$ & $\begin{array}{l}-0.003 \\
(0.005)\end{array}$ \\
\hline $\log \left(\right.$ Average distance $\left._{j t}\right)$ & $\begin{array}{l}0.004^{*} \\
(0.002)\end{array}$ & $\begin{array}{c}0.005^{* *} \\
(0.002)\end{array}$ & $\begin{array}{c}0.004^{* *} \\
(0.002)\end{array}$ & $\begin{array}{c}0.002 \\
(0.002)\end{array}$ & $\begin{array}{c}0.000 \\
(0.001)\end{array}$ & $\begin{array}{c}0.002 \\
(0.002)\end{array}$ \\
\hline Total fatalities ${ }_{i s t}$ & -0.002 & -0.001 & -0.003 & -0.003 & -0.002 & -0.001 \\
\hline $\log (1+$ safety violations ist $)$ & $\begin{array}{l}(0.004) \\
-0.000\end{array}$ & -0.002 & $\begin{array}{l}(0.003) \\
-0.000\end{array}$ & $\begin{array}{c}(0.003) \\
0.000\end{array}$ & $\begin{array}{c}(0.003) \\
0.001\end{array}$ & $\begin{array}{l}(0.001) \\
-0.000\end{array}$ \\
\hline $\log \left({\left.\text { Production } / \text { hours }_{i s t}\right)}\right.$ & $\begin{array}{c}(0.001) \\
0.002 \\
(0.011)\end{array}$ & $\begin{array}{l}(0.002) \\
-0.003 \\
(0.011)\end{array}$ & $\begin{array}{l}(0.001) \\
0.018^{*} \\
(0.010)\end{array}$ & $\begin{array}{c}(0.001) \\
0.017 \\
(0.011)\end{array}$ & $\begin{array}{c}(0.001) \\
0.001 \\
(0.006)\end{array}$ & $\begin{array}{l}(0.001) \\
0.015^{*} \\
(0.008)\end{array}$ \\
\hline $\log \left(\right.$ Production $\left._{\text {ist }}\right)$ & $\begin{array}{c}0.002 \\
(0.006)\end{array}$ & $\begin{array}{c}0.005 \\
(0.006)\end{array}$ & $\begin{array}{l}-0.004 \\
(0.005)\end{array}$ & $\begin{array}{l}-0.002 \\
(0.005)\end{array}$ & $\begin{array}{c}0.004 \\
(0.004)\end{array}$ & $\begin{array}{l}-0.005 \\
(0.004)\end{array}$ \\
\hline $\log \left(\right.$ Employees $\left._{i s t}\right)$ & $\begin{array}{c}-0.011^{* * *} * \\
(0.004)\end{array}$ & $\begin{array}{c}-0.010^{* * * *} \\
(0.004)\end{array}$ & $\begin{array}{c}-0.011^{* * *} \\
(0.003)\end{array}$ & $\begin{array}{c}-0.013^{* * *} \\
(0.004)\end{array}$ & $\begin{array}{c}-0.006^{* *} \\
(0.003)\end{array}$ & $\begin{array}{c}-0.006^{* * *} \\
(0.002)\end{array}$ \\
\hline $\log \left(\right.$ Hours $\left._{i s t}\right)$ & $\begin{array}{c}0.004 \\
(0.006)\end{array}$ & $\begin{array}{c}0.000 \\
(0.006)\end{array}$ & $\begin{array}{l}0.011^{*} \\
(0.006)\end{array}$ & $\begin{array}{c}0.008 \\
(0.006)\end{array}$ & $\begin{array}{l}-0.001 \\
(0.005)\end{array}$ & $\begin{array}{l}0.008^{*} \\
(0.004)\end{array}$ \\
\hline $\log \left(\right.$ Mines $\left._{s t}\right)$ & $\begin{array}{c}0.004^{* *} \\
(0.002)\end{array}$ & $\begin{array}{l}0.003^{*} \\
(0.002)\end{array}$ & $\begin{array}{c}0.000 \\
(0.002)\end{array}$ & $\begin{array}{l}-0.003 \\
(0.005)\end{array}$ & $\begin{array}{l}-0.004 \\
(0.004)\end{array}$ & $\begin{array}{c}0.000 \\
(0.003)\end{array}$ \\
\hline Ultimate parent age $_{s t}$ & $\begin{array}{l}-0.000 \\
(0.000)\end{array}$ & $\begin{array}{l}-0.000 \\
(0.000)\end{array}$ & $\begin{array}{c}0.000 \\
(0.000)\end{array}$ & $\begin{array}{c}0.000 \\
(0.003)\end{array}$ & $\begin{array}{l}-0.004 \\
(0.003)\end{array}$ & $\begin{array}{c}0.004 \\
(0.003)\end{array}$ \\
\hline Operator age ${ }_{i s t}$ & $\begin{array}{c}0.000 \\
(0.000)\end{array}$ & $\begin{array}{c}0.000 \\
(0.000)\end{array}$ & $\begin{array}{c}0.000 \\
(0.000)\end{array}$ & $\begin{array}{l}0.000^{*} \\
(0.000)\end{array}$ & $\begin{array}{c}0.000 \\
(0.000)\end{array}$ & $\begin{array}{l}0.000 \\
(0.000)\end{array}$ \\
\hline Unionized $_{i s t}$ & $\begin{array}{c}0.004 \\
(0.008)\end{array}$ & $\begin{array}{c}0.009 \\
(0.009)\end{array}$ & $\begin{array}{l}-0.000 \\
(0.006)\end{array}$ & $\begin{array}{l}-0.010 \\
(0.010)\end{array}$ & $\begin{array}{l}-0.005 \\
(0.007)\end{array}$ & $\begin{array}{l}-0.006 \\
(0.007)\end{array}$ \\
\hline Year FE & No & Yes & $\mathrm{Ye}$ & Yes & Yes & Yes \\
\hline County FE & No & No & Yes & Yes & Yes & Yes \\
\hline Inspection office FE & No & No & Yes & Yes & Yes & Yes \\
\hline Ultimate Parent FE & No & No & No & Yes & Yes & Yes \\
\hline Number of firms & 927 & 927 & 921 & 744 & 744 & 744 \\
\hline Observations & 11,009 & 11,009 & 10,979 & 10,802 & 10,802 & 10,802 \\
\hline$R^{2}$ & 0.007 & 0.019 & 0.175 & 0.317 & 0.326 & 0.280 \\
\hline
\end{tabular}


Figure 1: Geographic Dispersion of Mines

This figure displays the geographic locations of the mines in our sample by public listing status of the ultimate parent. Privately-held mines are depicted with red dots and publicly-held mines are depicted with blue dots. Data on coal mine locations are from the Mine Safety and Health Administration (MSHA) published through an Open Government Initiative. Data on listing status are hand-collected from firm filings, CRSP, CapitalIQ, and data on IPO dates from Jay Ritter's website.

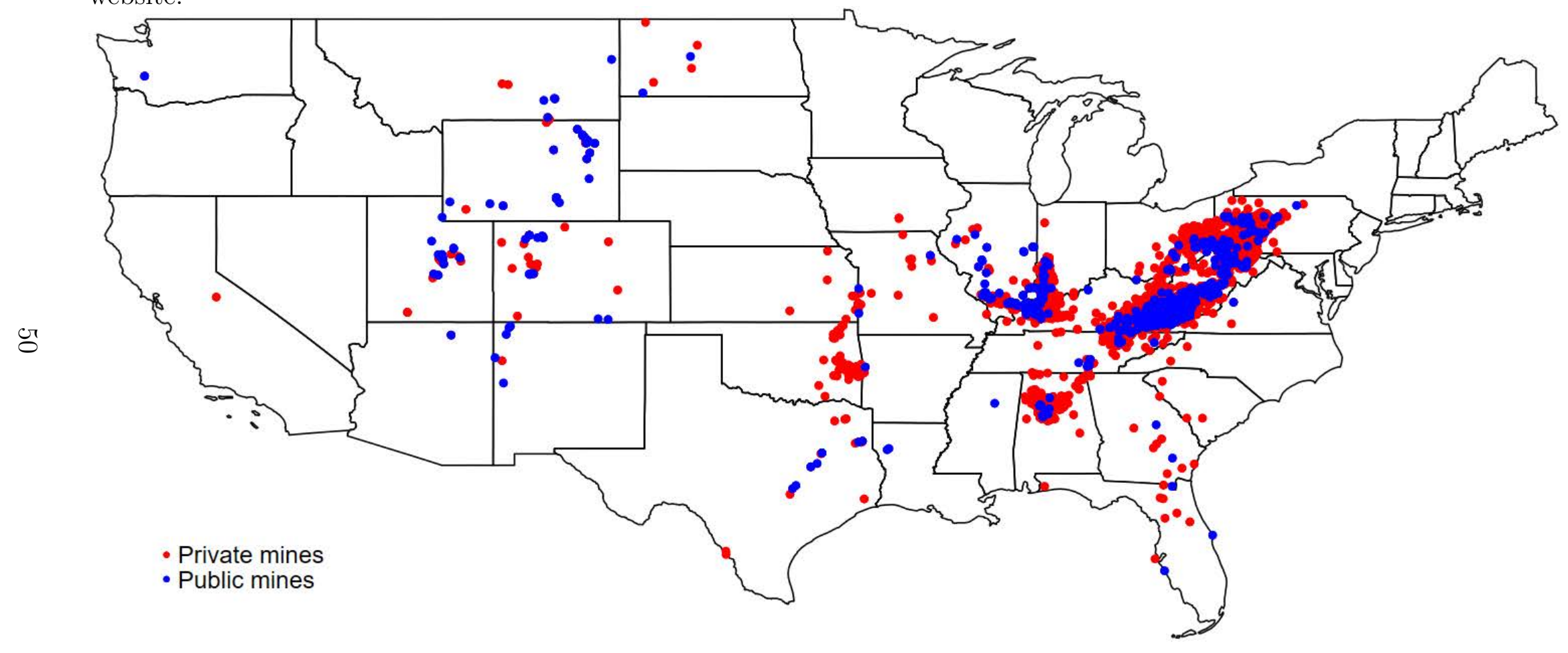


Figure 2: Listing Status and Annual Coal Mining Safety Violations

This figure displays annual coal mining safety violations over a sample period of 1993 through 2018. The gray line depicts annual mining safety violations in all coal mines operated in the United States, while the blue and red bars depict annual mining safety violations in coal mines in our main sample that are operated in the United States by public and private firms, respectively. Data on coal mining safety violations are from the Mine Safety and Health Administration (MSHA) published through an Open Government Initiative. Data on listing status are hand-collected from firm filings, CRSP, CapitalIQ, and data on IPO dates from Jay Ritter's website.

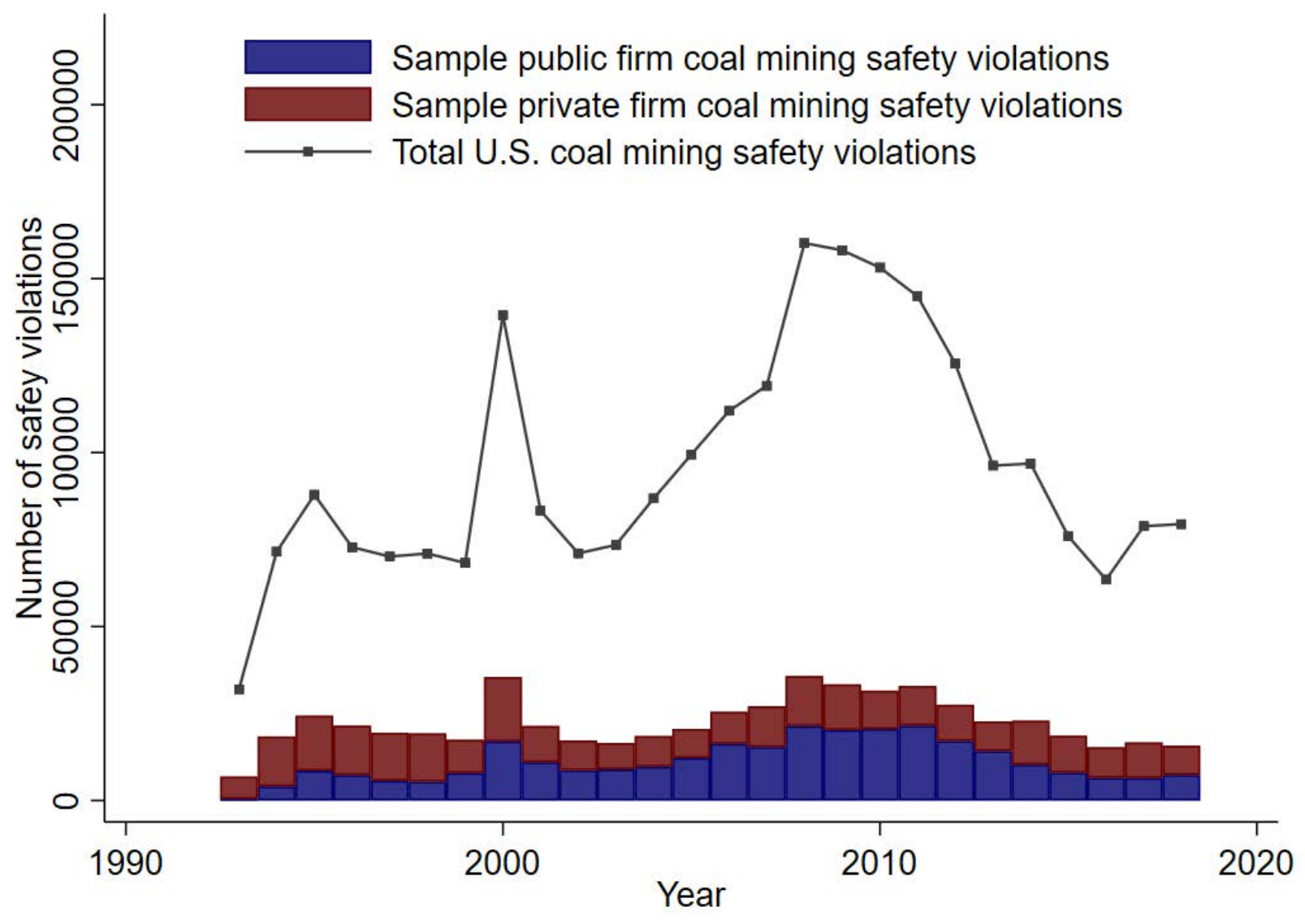


Figure 3: Listing Status and Annual Coal Mining Fatalities

This figure displays annual coal mining fatalities over a sample period of 1985 through 2018. The gray line depicts annual mining fatalities in all coal mines operated in the United States, while the blue and red bars depict annual mining fatalities in coal mines in our main sample that are operated in the United States by public and private firms, respectively. Data on coal mining fatalities are from the Mine Safety and Health Administration (MSHA) published through an Open Government Initiative. Data on listing status are hand-collected from firm filings, CRSP, CapitalIQ, and data on IPO dates from Jay Ritter's website.

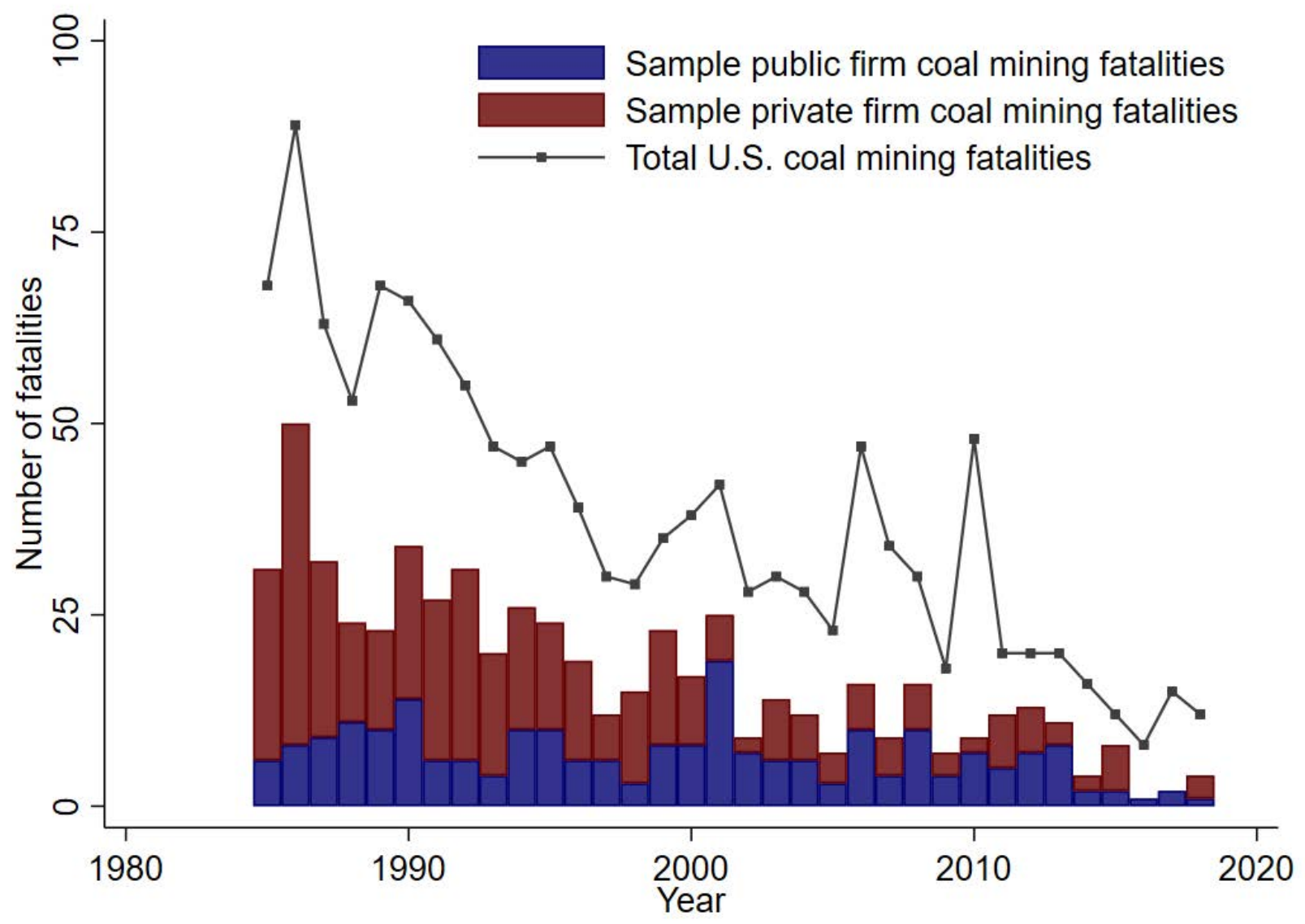


Figure 4: Annual Number of Mines Changing Listing Status

This figure displays the annual number of mines changing listing status over a sample period of 1985 through 2018. The blue bars depict mines that change listing status when the ultimate parent either goes public through an IPO, or goes private through a going-private transaction. The red bars depict mines that change status when a public firm acquires a privately-owned mine (or in most cases, the entire private firm), or when a private firm acquires a publiclyowned mine or an entire public firm through a reverse merger transaction. Data on ultimate mine ownership and mining acquisitions are from the Mine Safety and Health Administration (MSHA) published through an Open Government Initiative. Data on listing status are handcollected from firm filings, CRSP, CapitalIQ, and data on IPO dates from Jay Ritter's website.

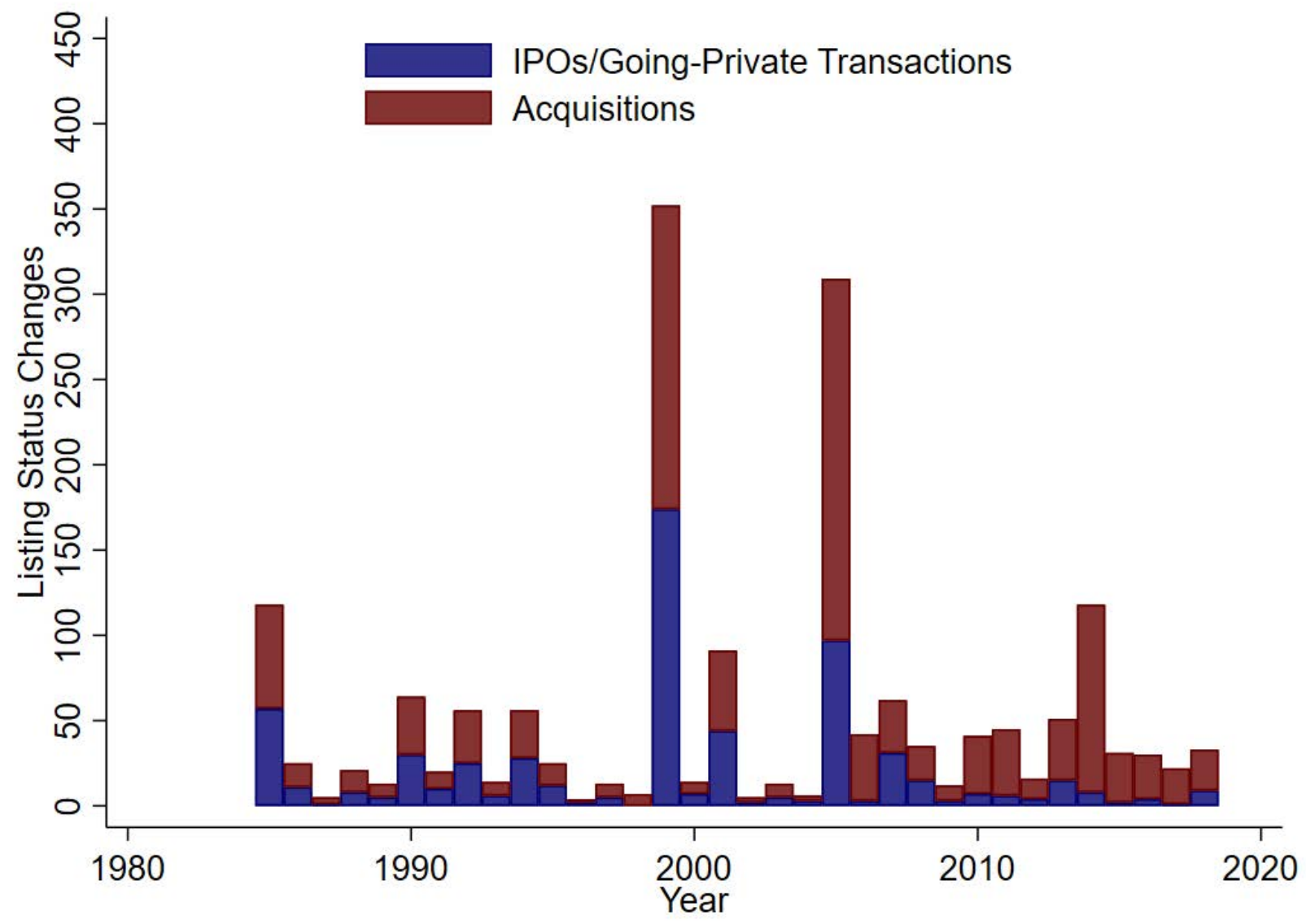




\section{Figure 5: Listing Status Changes and Mine-level Safety Violations Trends}

These figures display the trends of mine-level safety violations around changes in listing status for U.S. coal mines over a sample period of 1993 through 2018. The figures plot annual coefficients for each time (year $t \leq-3$ through year $t \geq 3$ ) directly around a listing status change interacted with an indicator for whether a firm is public at anytime in our sample. The models include the same controls and fixed effects as Models (2), (4), (6), and (8) in Table 3. Data on mine-level fatalities and safety violations, as well as ultimate mine ownership and mining acquisitions, are from the Mine Safety and Health Administration (MSHA) published through an Open Government Initiative. Data on firms' listing status are hand-collected from firm filings, CRSP, CapitalIQ, and data on IPO dates from Jay Ritter's website.

(a) All safety violations

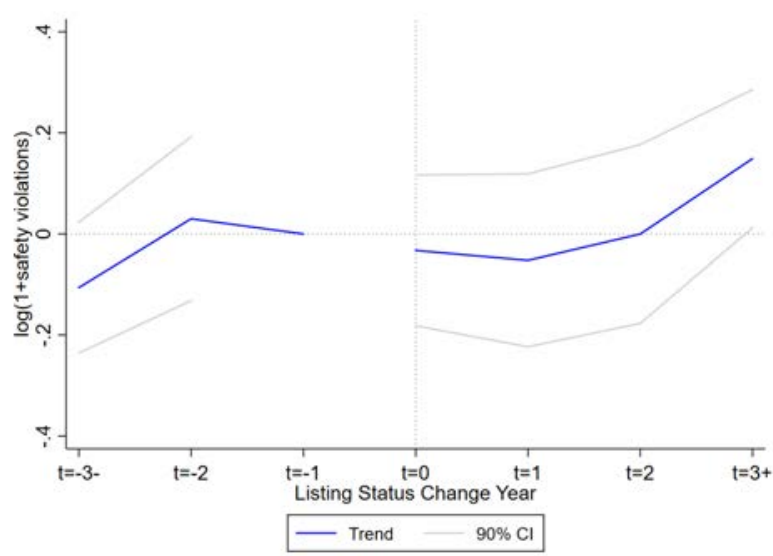

(c) High probability safety violations

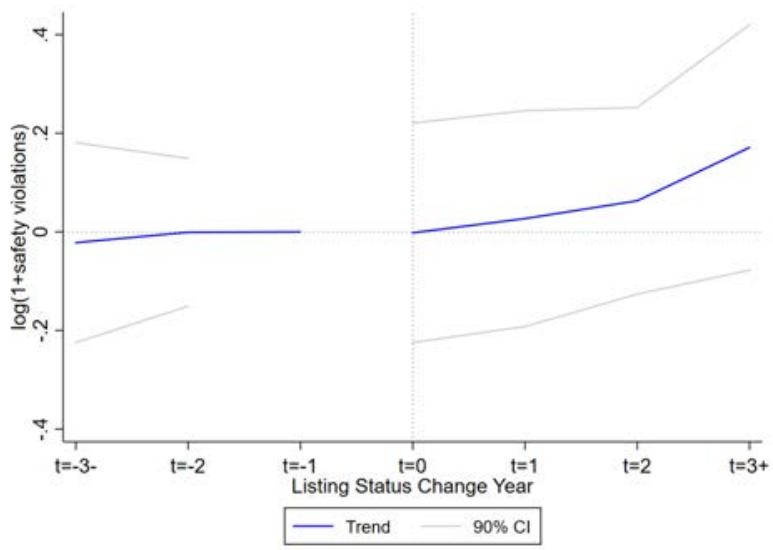

(b) Low probability safety violations

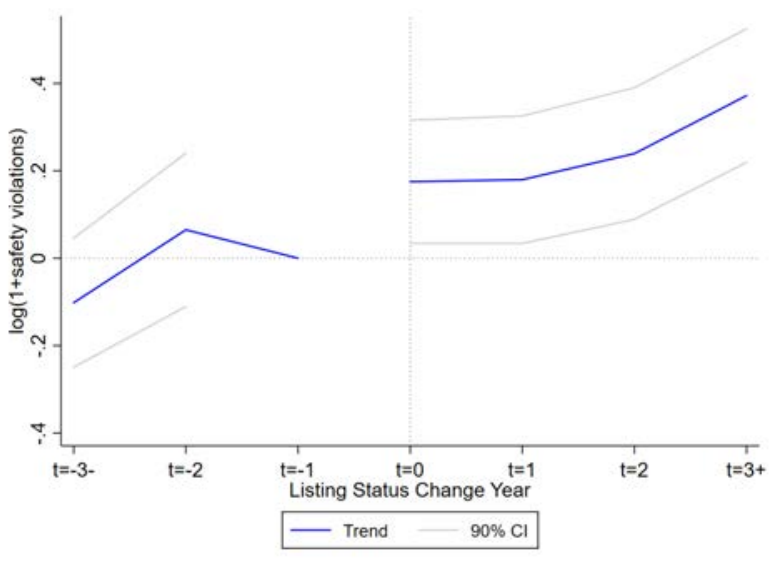

(d) High probability safety violations

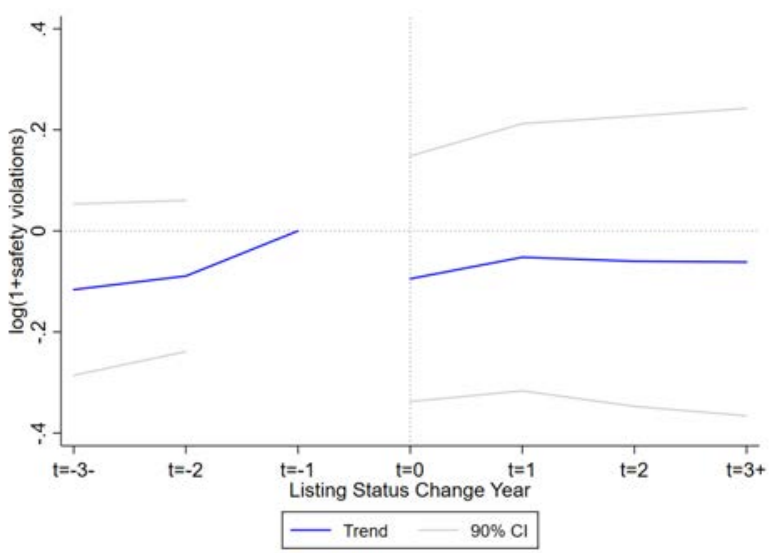


Figure 6: Listing Status Changes and Mine-level Fatalities Trends

This figure displays the trend of mine-level fatalities around changes in listing status for U.S. coal mines over a sample period of 1985 through 2018. The figures plot annual coefficients for each time (year $t \leq-3$ through year $t \geq 3$ ) directly around a listing status change interacted with an indicator for whether a firm is public at anytime in our sample. The model includes the same controls and fixed effects as Model (4) in Table 4. Data on mine-level production and employment, as well as ultimate mine ownership and mining acquisitions, are from the Mine Safety and Health Administration (MSHA) published through an Open Government Initiative. Data on firms' listing status are hand-collected from firm filings, CRSP, CapitalIQ, and data on IPO dates from Jay Ritter's website.
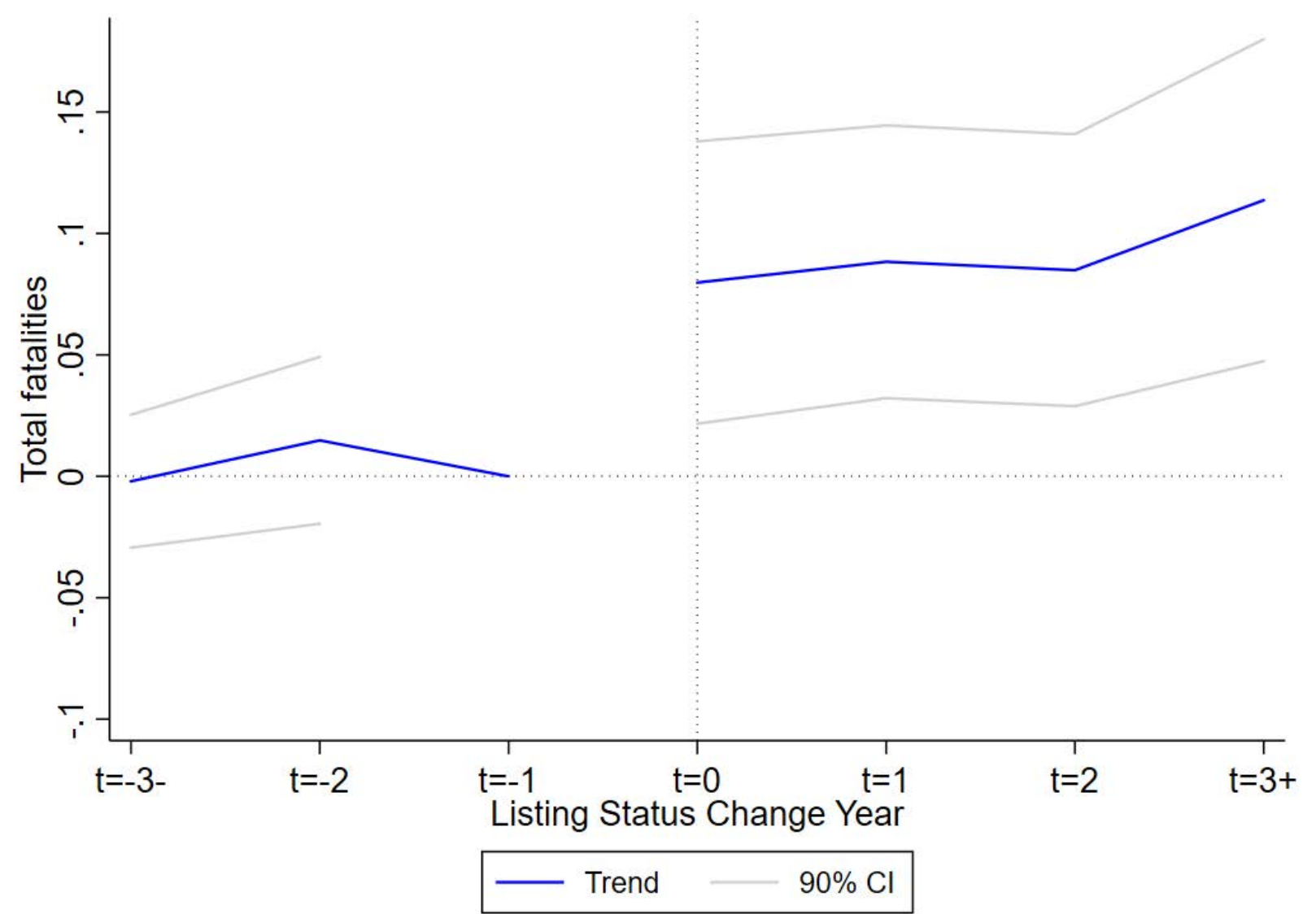
Figure 7: Listing Status Changes and Mine-level Productivity Trends

This figure displays the trend of mine-level productivity (measured by the natural log of tons of clean coal produced per worker hour) around changes in listing status for U.S. coal mines over a sample period of 1985 through 2018. The figures plot annual coefficients for each time (year $t \leq-3$ through year $t \geq 3$ ) directly around a listing status change interacted with an indicator for whether a firm is public at anytime in our sample. The model includes the same controls and fixed effects as Model (4) in Table 4. Data on mine-level production and employment, as well as ultimate mine ownership and mining acquisitions, are from the Mine Safety and Health Administration (MSHA) published through an Open Government Initiative. Data on firms' listing status are hand-collected from firm filings, CRSP, CapitalIQ, and data on IPO dates from Jay Ritter's website.

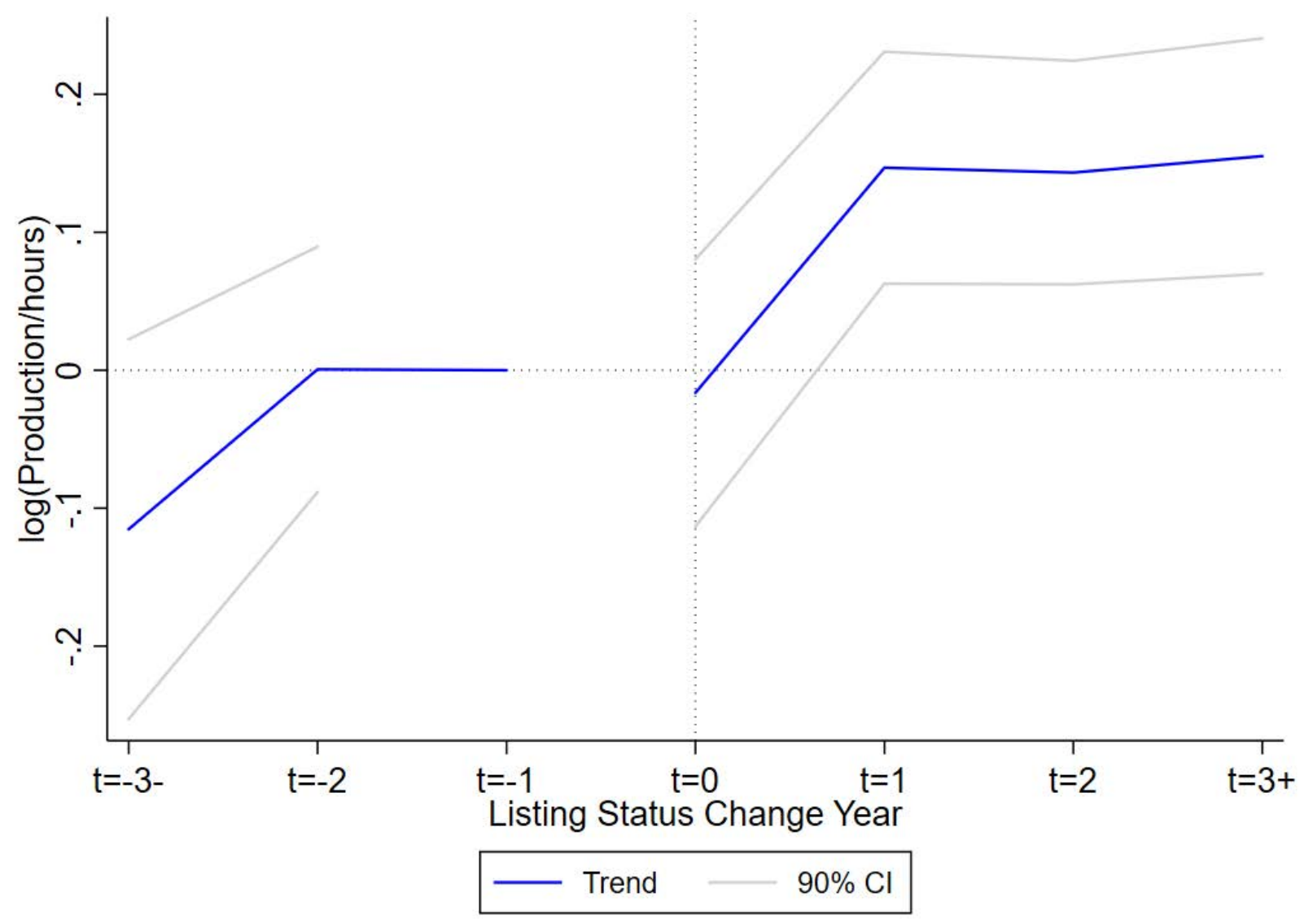




\section{Figure 8: Average Annual Coal Sale Prices}

These figures display average annual coal sales prices reported by the U.S. Energy Information Administration (EIA) from 1993 to 2018. Panel A displays the average annual price level across the entire U.S. for both surface and underground coal, as well as surface coal for Ohio and underground coal for Colorado. These two states serve as examples for the overall level of dispersion in prices by state and mine type. Panel B displays the average annual sales price change (year-over-year) for each state separated by surface and underground coal mining. The size of the bubbles reflects the level of the price prior to the change. Thus, larger bubbles highlight larger year-over-year dollar changes in the average annual sale price. For aesthetic purposes, we exclude price increases above $50 \%$, and price decreases below $-50 \%$. There are only seven such observations.

(a) Average Sale Price Level

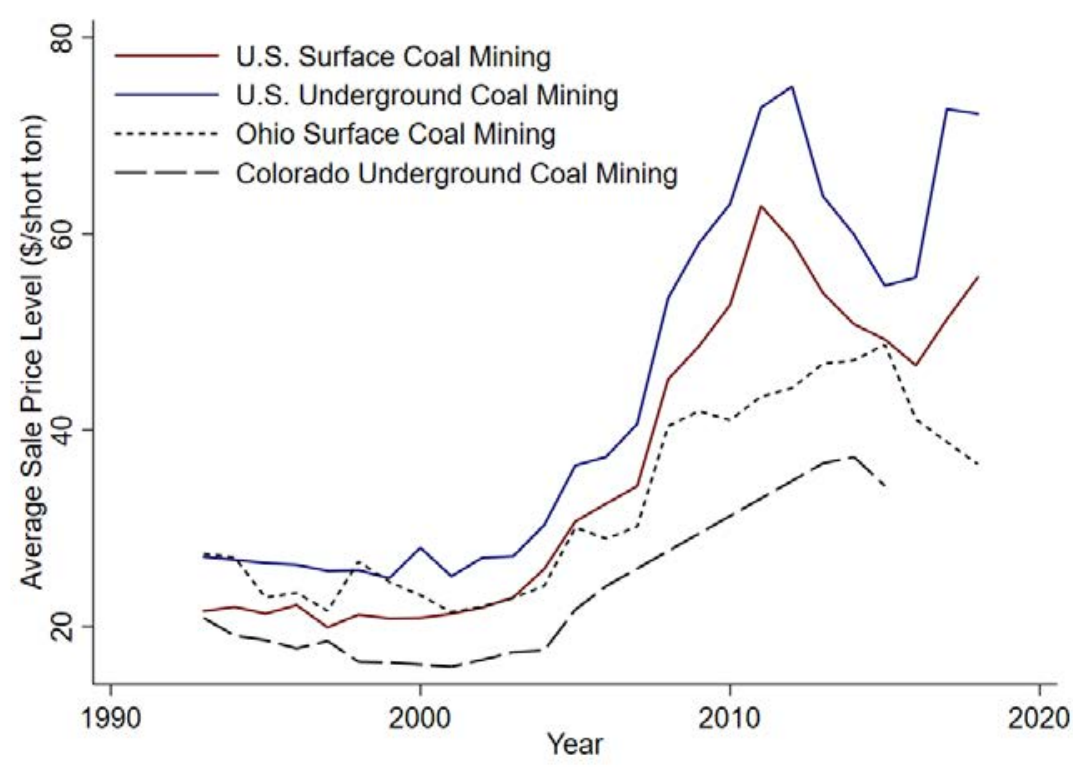

(b) Average Sale Price Percentage Change (YOY)

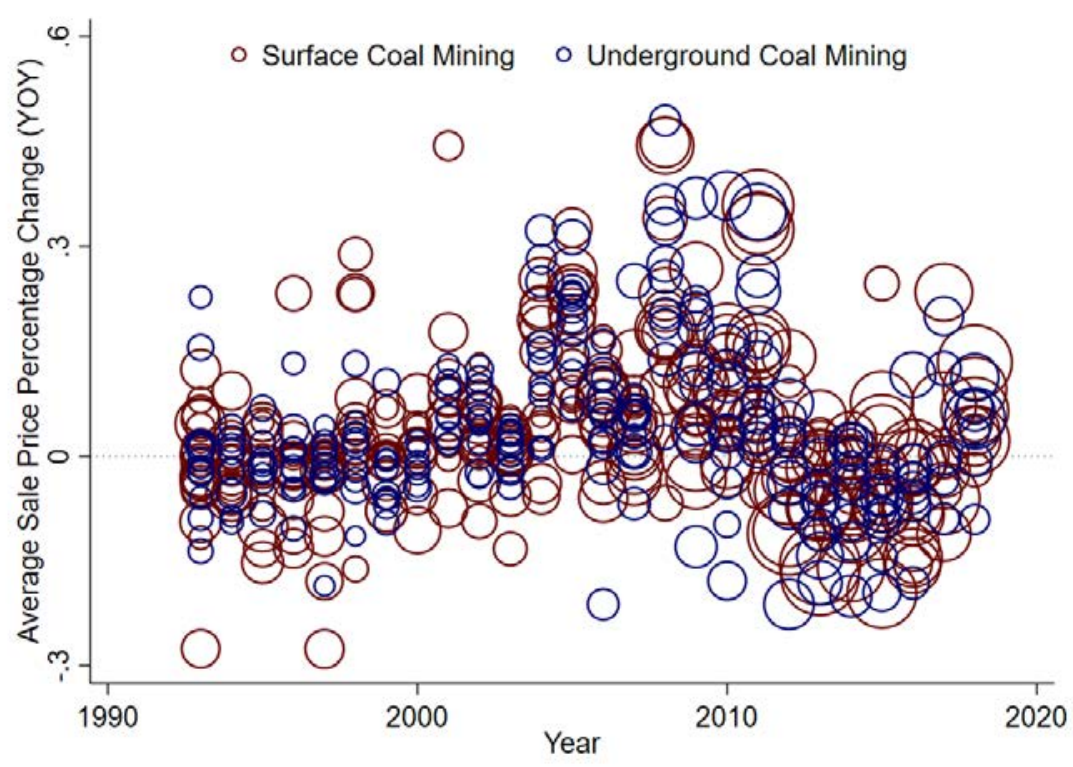


Figure 9: MSHA Inspection Office Reassignments

These figures display two examples of mines that experience MSHA inspection office reassignments. Panel A displays a MSHA inspection office move from McAlester, Oklahoma to Longview, Texas in 2013. This move affects six mines in our sample, five in which the proximity to the MSHA office decreases (indicated by red dots), and one mine in which the proximity to the MSHA office increases (indicated by the green dot). Each of these six changes is greater than 60 miles and so each of these mines is treated. Panel B displays MSHA inspection office reassignments from Jasper to Bessemer, Alabama in the late 1990s and early 2000s. These reassignments affect ten mines in our sample. Three of these mines (indicated by red dots) experience a mileage change of greater than 60 miles and so are treated, while the other seven mines (indicated by green dots) experience a mileage change of less than 60 miles and so are part of the control group.

(a) McAlester, OK to Longview, TX

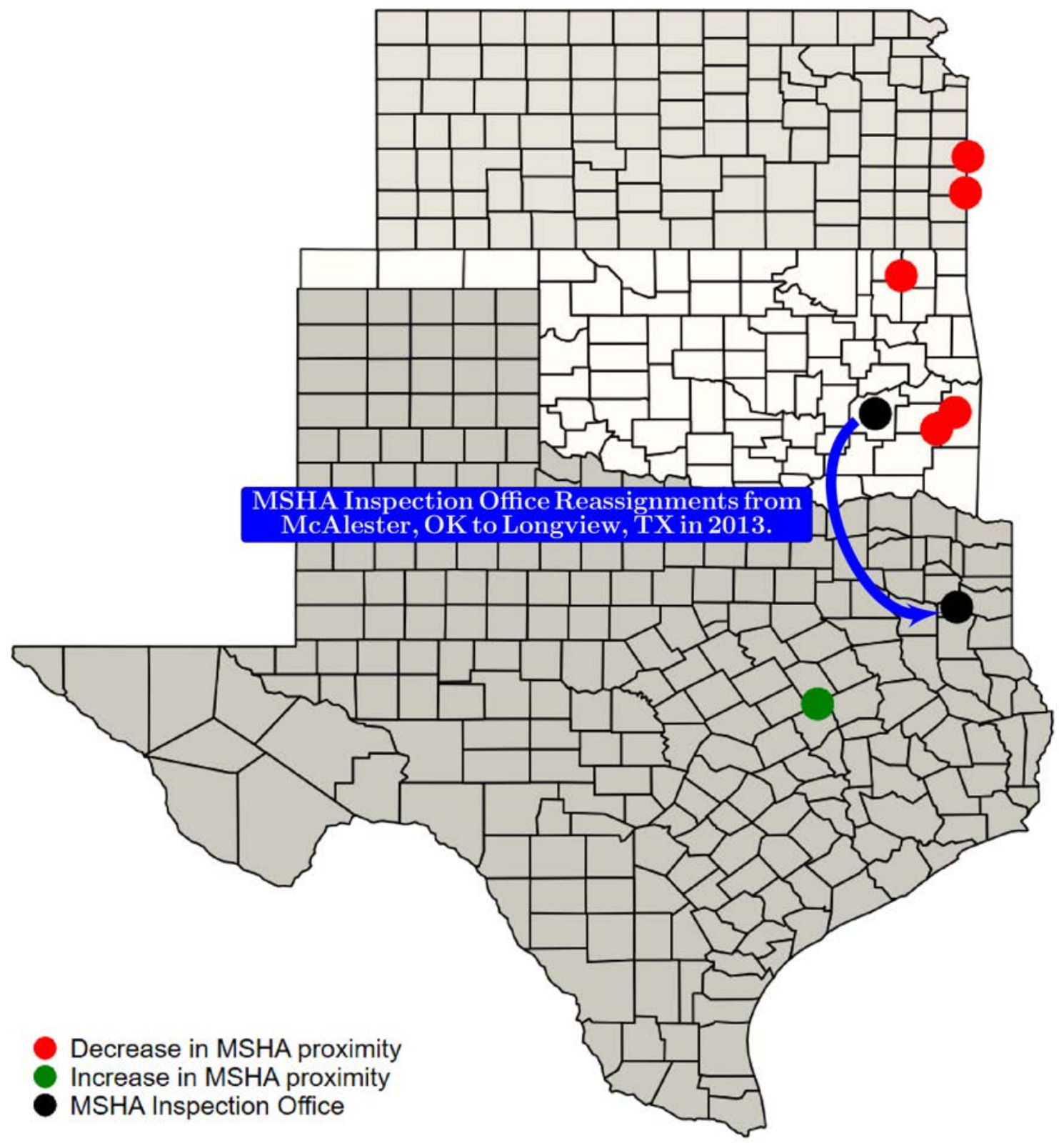


(b) Jasper, AL to Bessemer, AL

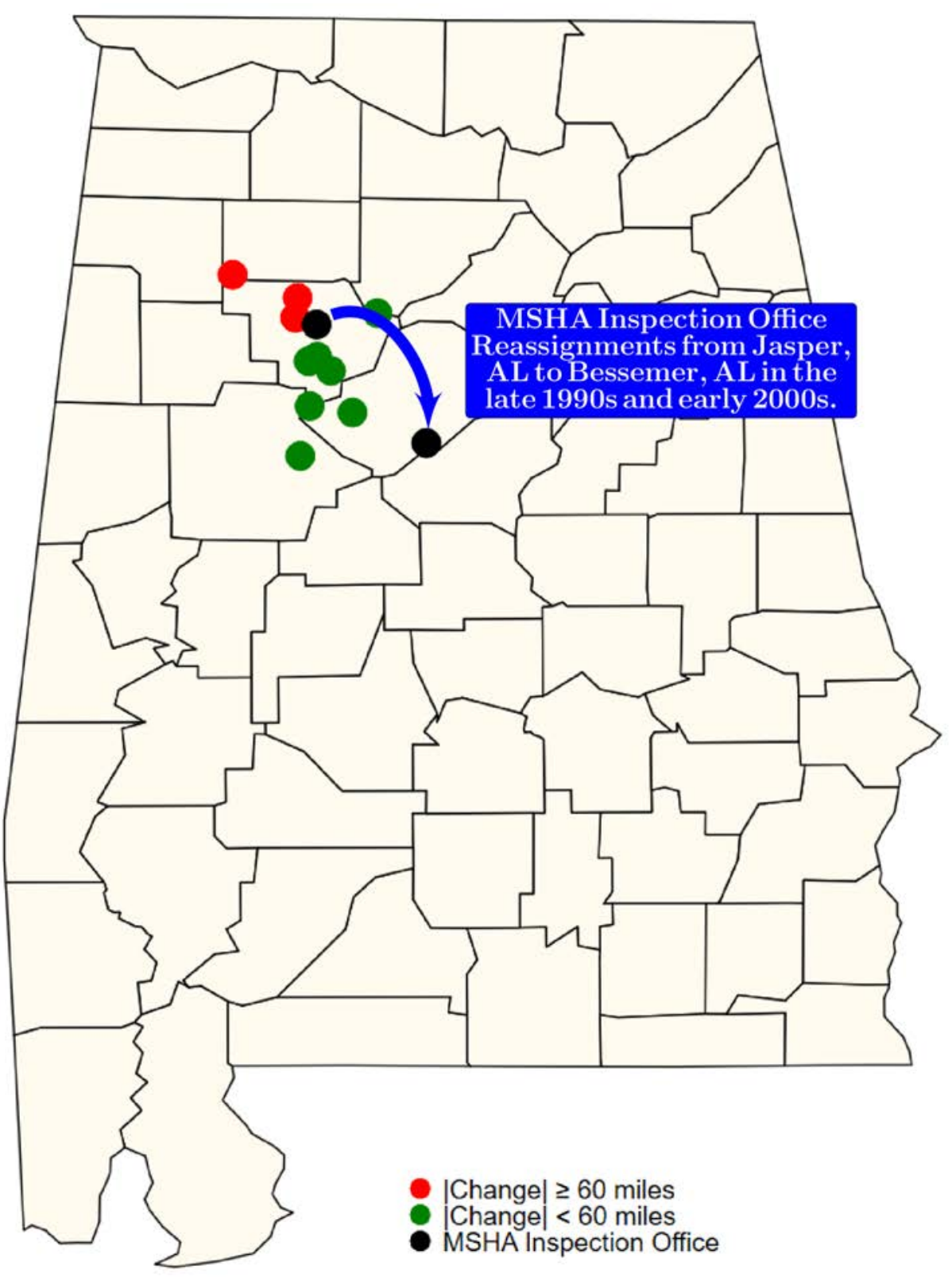




\section{A Appendix}

Table A.1: Data Appendix

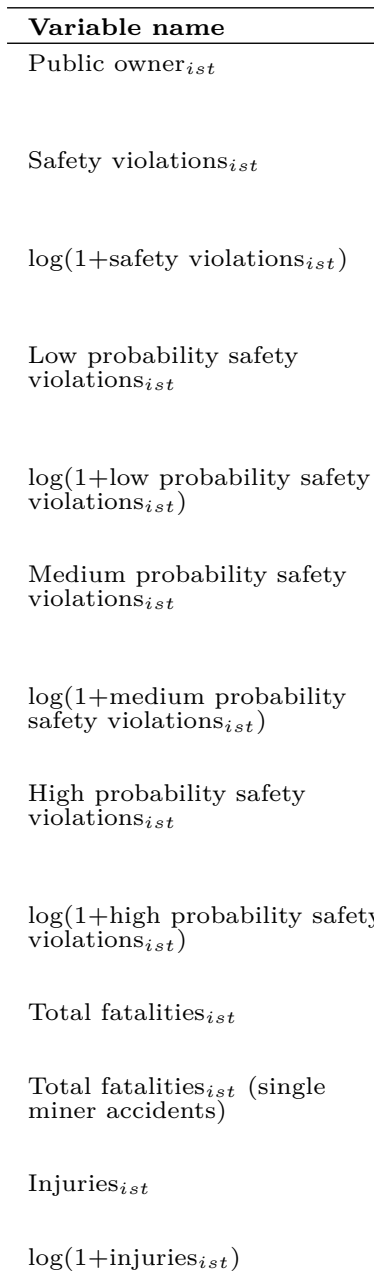

Days missed due to injury ${ }_{i s t}$

$\log \left(1+\right.$ days $\left._{\text {missed }_{i s t}}\right)$

Days missed per injuryist

$\log (1+$ days

missed/injuries ist $)$

Fines paid $_{i s t}$

$\log \left(1+\right.$ fines $\left._{i s t}\right)$

\section{Definition}

Indicator variable equal to one if a mine $i$ 's ultimate parent owner, $s$, is publicly listed in year $t$

The number of citations issued by MSHA for safety violations at mine $i$, owned by ultimate parent $s$ in year $t$

Natural log of one plus the number of citations issued by MSHA for safety violations at mine $i$, owned by ultimate parent $s$ in year $t$

The number of citations issued by MSHA for safety violations that are deemed low probability of the accident at mine $i$, owned by ultimate parent $s$ in year $t$

Natural log of one plus the number of low probability safety violations at mine $i$, owned by ultimate parent $s$ in year $t$

The number of citations issued by MSHA for safety violations that are deemed medium probability of the accident at mine $i$, owned by ultimate parent $s$ in year $t$

Natural log of one plus the number of medium probability safety violations at mine $i$, owned by ultimate parent $s$ in year $t$

The number of citations issued by MSHA for safety violations that are deemed high probability of the accident at mine $i$, owned by ultimate parent $s$ in year $t$

Natural log of one plus the number of high probability safety violations at mine $i$, owned by ultimate parent $s$ in year $t$

The number of fatalities reported to MSHA at mine $i$, owned by ultimate parent $s$ in year $t$

The number of fatalities from accidents only involving a single miner reported to MSHA at mine $i$, owned by ultimate parent $s$ in year $t$

The number of injuries reported to MSHA at mine $i$, owned by ultimate parent $s$ in year $t$

Natural log of one plus the number of injuries at mine $i$, owned by ultimate parent $s$ in year $t$

The total number of days workers are estimated to miss for injuries at mine $i$, owned by ultimate parent $s$ in year $t$

Natural log of one plus the number of days estimated to be missed at mine $i$, owned by ultimate parent $s$ in year $t$

The total number of days estimated to be missed divided by the total number of injuries at mine $i$, owned by ultimate parent $s$ in year $t$ (winsorized at the $1 \%$ and $99 \%$ levels)

Natural log of one plus the number of days estimated to be missed divided by the number of injuries at mine $i$, owned by ultimate parent $s$ in year $t$

Total fines paid by the controller to MSHA for citations from safety violations or accidents at mine $i$, owned by ultimate parent $s$ in year $t$

Natural log of one plus the total fines paid at mine $i$, owned by ultimate parent $s$ in year $t \mathrm{n}$
Source

Firm filings, CRSP, Capital IQ and data on IPO dates from Jay Ridder's website

Mine Safety and Health Administration

Mine Safety and Health Administration

Mine Safety and Health Administration

Mine Safety and Health Administration

Mine Safety and Health Administration

Mine Safety and Health Administration

Mine Safety and Health Administration

Mine Safety and Health Administration

Mine Safety and Health Administration

Mine Safety and Health Administration

Mine Safety and Health Administration

Mine Safety and Health Administration

Mine Safety and Health Administration

Mine Safety and Health Administration

Mine Safety and Health Administration

Mine Safety and Health Administration

Mine Safety and Health Administration

Mine Safety and Health Administration 
Table A.1-continued

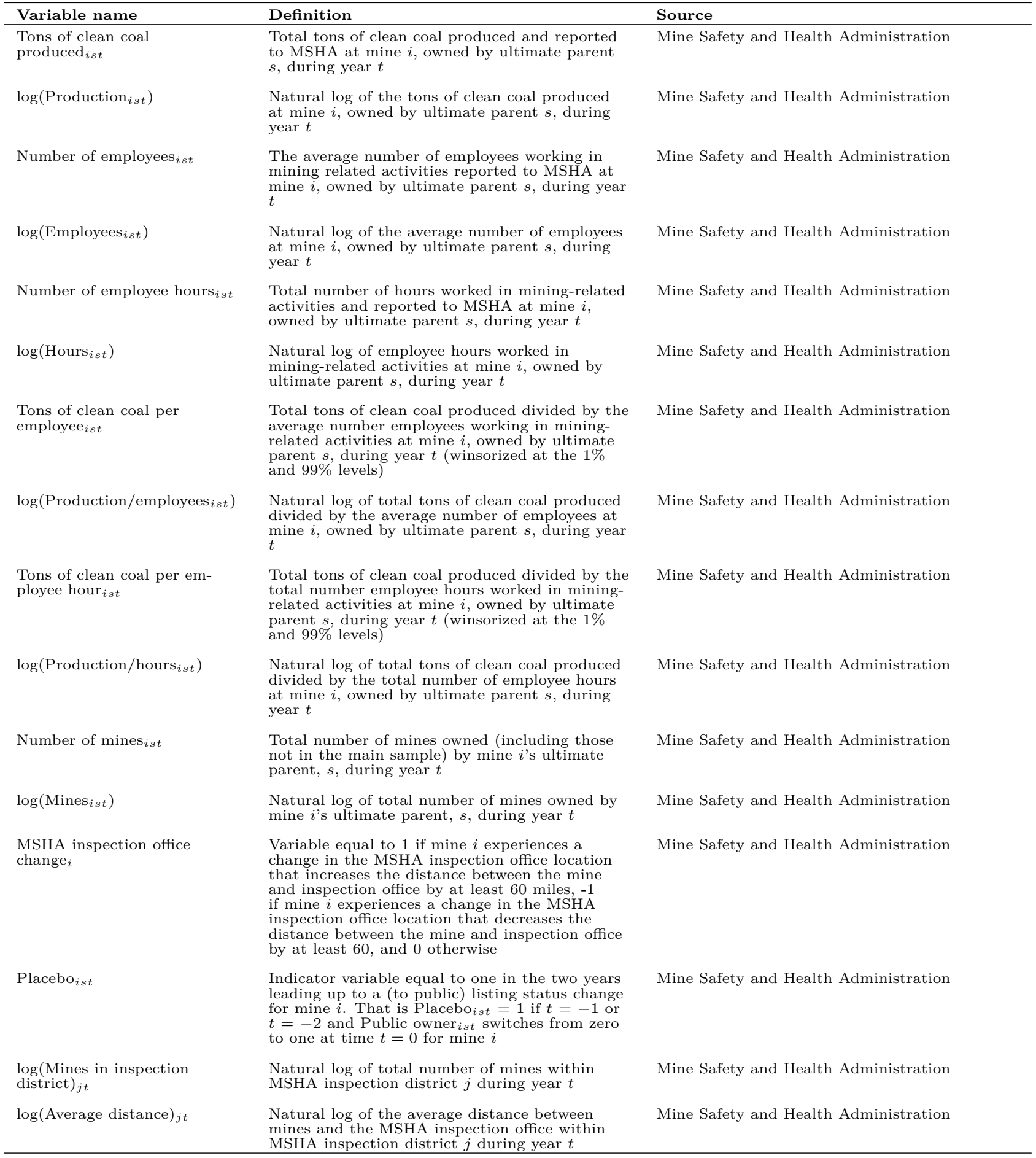

